\title{
Capsular polysaccharide inhibits adhesion of Bifidobacterium longum 105-A to enterocyte-like Caco-2 cells and phagocytosis by macrophages
}

Amin Tahoun ${ }^{1,2 \dagger}{ }^{,}$, Hisayoshi Masutani ${ }^{1 \dagger}$, Hanem El-Sharkawy ${ }^{2,3}$, Trudi Gillespie ${ }^{4}$, Ryo P. Honda ${ }^{5}$, Kazuo Kuwata ${ }^{6,7,8}$, Mizuho Inagaki ${ }^{1,9}$, Tomio Yabe ${ }^{1,8,9}$, Izumi Nomura ${ }^{1}$ and Tohru Suzuki 1,9*

\begin{abstract}
Background: Bifidobacterium longum 105-A produces markedly high amounts of capsular polysaccharides (CPS) and exopolysaccharides (EPS) that should play distinct roles in bacterial-host interactions. To identify the biological function of B. longum 105-A CPS/EPS, we carried out an informatics survey of the genome and identified the EPS-encoding genetic locus of B. longum 105-A that is responsible for the production of CPS/EPS. The role of CPS/EPS in the adaptation to gut tract environment and bacteria-gut cell interactions was investigated using the $\triangle$ cpsD mutant.

Results: A putative B. longum 105-A CPS/EPS gene cluster was shown to consist of 24 putative genes encoding a priming glycosyltransferase (cpsD), 7 glycosyltransferases, 4 CPS/EPS synthesis machinery proteins, and 3 dTDP-Lrhamnose synthesis enzymes. These enzymes should form a complex system that is involved in the biogenesis of CPS and/or EPS. To confirm this, we constructed a knockout mutant ( $\triangle c p s D)$ by a double cross-over homologous recombination. Compared to wild-type, the $\triangle c p s D$ mutant showed a similar growth rate. However, it showed quicker sedimentation and formation of cell clusters in liquid culture. EPS was secreted by the $\triangle \operatorname{cps} D$ mutant, but had altered monosaccharide composition and molecular weight. Comparison of the morphology of B. longum 105-A wild-type and $\triangle c p s D$ by negative staining in light and electron microscopy revealed that the formation of fimbriae is drastically enhanced in the $\triangle c p s D$ mutant while the B. longum 105-A wild-type was coated by a thick capsule. The fimbriae expression in the $\triangle c p s D$ was closely associated with the disappearance of the CPS layer. The wild-type showed low $\mathrm{pH}$ tolerance, adaptation, and bile salt tolerance, but the $\triangle c p s D$ mutant had lost this survivability in gastric and duodenal environments. The $\triangle c p s D$ mutant was extensively able to bind to the human colon carcinoma Caco-2 cell line and was phagocytosed by murine macrophage RAW 264.7, whereas the wild-type did not bind to epithelial cells and totally resisted internalization by macrophages.
\end{abstract}

Conclusions: Our results suggest that CPS/EPS production and fimbriae formation are negatively correlated and play key roles in the survival, attachment, and colonization of B. longum 105-A in the gut.

Keywords: Bifidobacterium longum 105-A, Capsular polysaccharides, Caco-2 cell line, RAW 264.7, Cell adhesion, Phagocytosis

\footnotetext{
${ }^{*}$ Correspondence: suzuki@gifu-u.ac.jp

${ }^{\dagger}$ Amin Tahoun, Hisayoshi Masutani contributed equally to this work

1 Faculty of Applied Biological Sciences, Gifu University, 1-1 Yanagido,

Gifu 501-1193, Japan

Full list of author information is available at the end of the article
} 


\section{Background}

The intestinal tract is considered to be one of the most densely colonized ecosystems of the human body and is colonized by trillions of microorganisms shortly after birth [1-4]. These organisms have been shown to have a significant symbiotic role in human health and nutrition, preventing pathogen colonization and maintaining mucosal immunity while being provided with access to key nutrients and a stable growth environment in the human intestine [5]. To date, over 1000 microbial species, mostly bacterial and anaerobic, have been cultured from the human intestinal microbiome [6]. Of these, Bifidobacteria and Lactobacilli are two of the most dominant genera conferring specific health benefits on their host [7].

The term probiotic was defined by Roy Fuller in 1989 [8] as a live microbial feed supplement that positively affects the host animal by improving its intestinal microbial balance. Moreover, probiotic bacteria are reported to have immunomodulation effects [9], anti-allergic effects $[10,11]$, the ability to inhibit hyperglycemia [12], and anti-hypertensive activity [13]. Bifidobacterium is one of the most commonly used probiotics in dairy products for human consumption [14-16].

Bifidobacteria are members of the Actinobacteria phylum; they are gram-positive, non-motile, anaerobic, nonfilamentous rods with 'bifido' (branching) shape [17]. It was first isolated from the feces of a healthy infant by Henry Tissier, a French pediatrician at the Pasteur Institute in 1899 [18]. In general, it colonizes the colon rather than small intestine and can be isolated from the intestinal tract and feces of mammals, birds, fishes, and insects [19-21]. The ingestion of Bifidobacteria effects the prevention of constipation [22], an increase in calcium absorption from the gut [23], a reduction in the relapse frequency of ulcerative colitis [24], inhibition of cancer cell growth [25], and tumor growth [26]. It also suppresses the inflammation by the production of serpin [27] and suppresses the growth of pathogenic bacteria, such as E. coli O157:H7, by the production of acetic acid [28].

Nevertheless, the molecular mechanisms by which Bifidobacteria maintain a niche within their host and provide these effects are mostly still unknown [29].

The production of surface exopolysaccharide by probiotic bacteria is one of the proposed mechanisms by which these beneficial microbes facilitate commensalhost interaction and infer reported health benefits [30, 31]. Interest in bacterial polysaccharides has stemmed from the use of these economically important carbohydrate polymers in the food and biotechnology sectors, as well as their implications for health [32, 33]. Most bacteria produce more than one extracellular surface polysaccharide, such as lipopolysaccharides (O-antigens), capsular polysaccharide (CPS), and exopolysaccharide (EPS). EPS is thought to be released from cell-wall CPS [34-40]; thus, distinguishing between CPS and EPS is difficult. CPS/EPS consists of branched repeating units of sugar or sugar derivatives; mainly D-glucose, D-galactose, L-rhamnose, D-mannose, $N$-acetylglucosamine, and $N$-acetyl galactosamine in variable ratios [41]. EPS can be classified into two groups, homo- or heteropolysaccharides, based on their monosaccharide composition [42]. In pathogenic bacteria, EPSs are thought to be critical in host-microbe interactions where they facilitate in adherence and colonization within the human host [43] and have a role in immunomodulation [44].

The precise biological role of EPS produced by commensal bacteria is less clear; however, recent work by Fanning et al. [31] reported a pivotal and beneficial role for EPS in modulating various aspects of Bifidobacteriahost interactions, including the ability of Bifidobacteria to remain immunologically silent and provide pathogen protection. Probiotic EPS is also reported to determine cell surface characteristics such as the formation of biofilms [45], the colonization [31], and immunomodulation [46]. It is also involved in the protection against toxic compounds [47], bacteriophages [48], osmotic stress, and strict conditions such as bile and acid [47]. It is reported that some Bifidobacteria produce the two (or more) types of EPS [49], and these molecules should have specific functions and play roles in their survival strategies.

The first publically available genome was that of $B$. longum NCC2705 [50], and the completed genomes of 29 Bifidobacteria are held within the Gene Bank database at the time of writing. However, there are limited reports in the literature with regard to the genetic analysis of EPS biosynthesis in Bifidobacterium species. The generation of gene-knockout mutants of Bifidobacteria has been hampered by their low transformation efficiencies [51, 52].

We have overcome this by 'Plasmid Artificial Modification (PAM)' by averting the restriction system of bacteria $[53,54]$ and a sophisticated shuttle vector, pKKT427 [53]. We also constructed a gene-knockout system using a temperature-sensitive plasmid [55], pyrE-dependent bidirectional selection marker [56], improved promoter [57] and oxygen tolerance [58]. By the combination of these molecular genetic tools, the construction of gene deletion in Bifidobacteria, using the double cross-over homologous recombination system, became available at the practical level $[55,56,59]$.

Bifidobacterium longum 105-A, which belongs to $B$. longum subsp. longum, was isolated from healthy human feces, and showed exceptionally high transformation efficiencies [60]. The whole genome sequence has been determined in our recent report [61]. Together with the 
ability to produce gene-knockout mutants with strain $B$. longum 105-A, it has opened the possibility to study the genetic basis of EPS biosynthesis in Bifidobacteria.

The initial step of the EPS-unit synthesis is catalyzed by priming glycosyltransferase (cpsD gene) [62]. B. longum 105-A harbors both a cpsD gene and six genes encoding glycosyltransferases, significantly more than the number of glycosyltransferases reported for other $B$. longum strains. We show that the symbiotic and probiotic B. longum 105-A contains an EPS-encoding genetic locus responsible for the production of EPS that provides resistance to both bile and acid treatment and is involved in the interaction of B. longum 105-A with intestinal epithelial cells and has a role in the resistance of Bifidobacteria to macrophage phagocytosis.

\section{Results}

Identifying of EPS locus and annotation of the putative EPS biosynthetic cluster in B. longum 105-A

The genome of B. longum 105-A [61] harbors a putative EPS-encoding locus, which extends from BL105A-0403 to $B L 105 A-0427$ and encompasses a $33.2-\mathrm{kb}$ region that harbors 24 genes predicted to be involved in EPS biosynthesis (Fig. 1; Table 1), four genes (BL105A_0403, BL105A_0419, BL105A_0421, and BL105A_0422) that encode a putative transposase, and three genes (BL105A_0418, BL105A_0421, and BL105A_0423) that encode a putative integrase. Half of these genes (i.e., 13 of 24) are organized into one gene set, while the remaining genes were organized into four smaller adjacent gene sets, putative operons, eps1 to 4 (Fig. 1). The 1st gene set, encompassing BL105A_0405 to BL105A_0407, is designated here as the eps1 operon. The 2nd and largest set is BL105A_0408 to BL105A_0413, as the eps2 operon. The 3rd operon is BL105A_0414 to BL105A_0417, as the eps3 operon. The 4th set, BL105A_0424 to BL105A_0427, is designated as the eps4 operon. The EPS gene cluster of B. longum 105-A is modular in the organization, which is commonly reported for surface heteropolysaccharides [63].

Located in the eps1 operon, the BL105A_0406 and BL105A_0407 genes encode proteins that are annotated as an envelope protein and a chain length determinant protein, respectively, which have a high homology to the putative Wzd-Wze tyrosine kinase complex of L. rhamnosus GG [64]. The Wzb protein of L. rhamnosus GC has been biochemically characterized as a copper-dependent O-phosphatase [65]. In Streptococci, Wzd-Wze complex has been shown to be an autophosphorylating tyrosine kinase activity and has a regulatory role in CPS biosynthesis and polymer export [66].

This EPS cluster of B. longum 105-A contains 6 putative glycosyltransferases (GTF) genes encoding enzymes for the biosynthesis of EPS that are located in eps2 operon and encompasses genes BL105A_0408 to BL105A_0413. Comparable genome analysis of EPS clusters of some lactic acid bacteria species by Ruas-Madiedo et al. [62] revealed that the core of the EPS cluster is also occupied by GTF genes involved in the synthesis of repeating EPS units. The EPS oligosaccharide unit is built up by the sequential reaction of GTF that catalyze the transfer of the sugar moieties from activated donor molecules stepby-step. Although multiples of GTF genes have been reported in EPS clusters of other B. longum strains [17], $B$. longum 105-A is unique in having 6 GTF genes that range in size from 533 to $1964 \mathrm{bp}$. The first two putative GTF genes, BL105A_0408 and BL105A_0409, have $100 \%$ amino acid homology to the previously identified $B$.

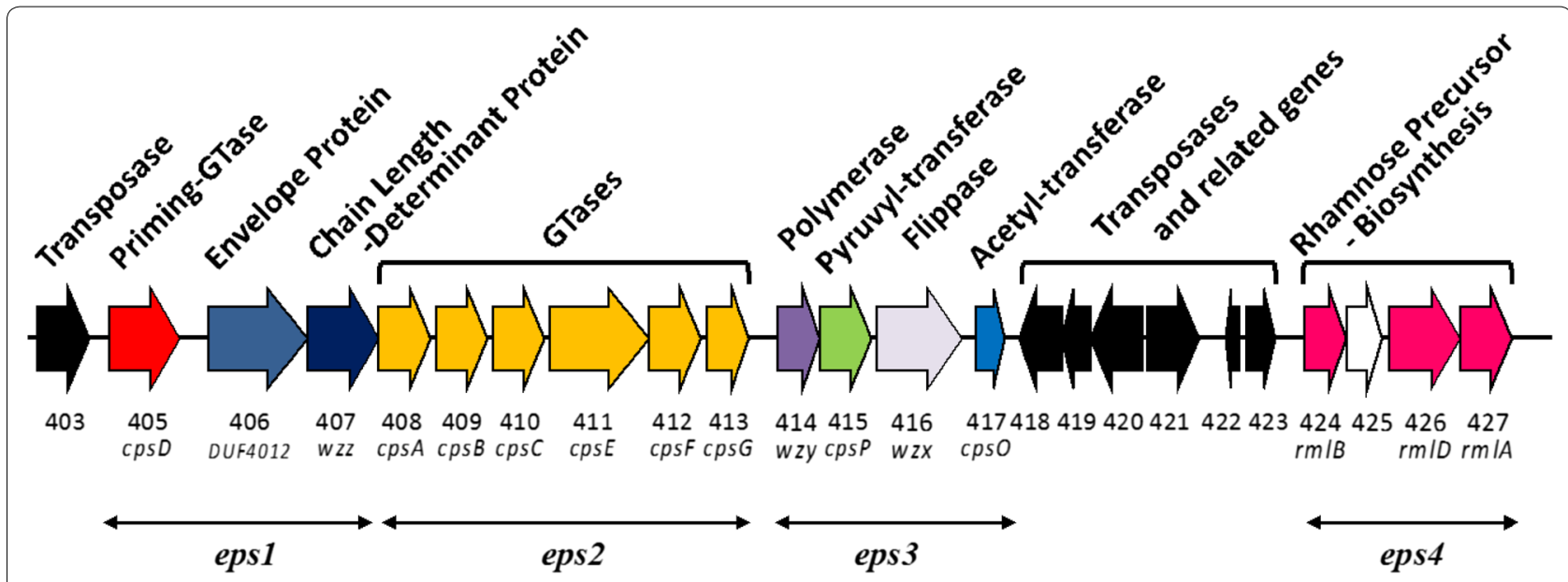

Fig. 1 CPS/EPS gene cluster of B. longum 105-A. The gene cluster from BL105A_0403 to BL105A_0427, which located nucleotide number 476,499509,716 , in genome sequence (AP014658) was shown. The enzyme and gene names, annotated by blast homology search (Table 1), were indicated. Putative operons, eps 1-4, were shown with arrows 
Table 1 ORFs identified in the EPS gene cluster of B. longum 105-A

\begin{tabular}{|c|c|c|c|c|c|c|}
\hline \multirow[t]{2}{*}{ ORF } & \multirow[t]{2}{*}{ Gene } & \multirow[t]{2}{*}{ Size (bp) } & \multirow[t]{2}{*}{ Predicted encoded function } & \multicolumn{2}{|l|}{ Best BLAST hit } & \multirow[t]{2}{*}{ Identity (\%) } \\
\hline & & & & Protein (accession no.) & Organism & \\
\hline BL105A_0403 & & 1272 & IS30 family transposase & WP_008783747.1 & MULTISPECIES & 99 \\
\hline BL105A_0405 & cpsD welE & 1476 & $\begin{array}{l}\text { Undecaprenyl-phosphate galactose } \\
\text { phosphotransferase; priming GTF }\end{array}$ & CCY95224 & B. longum CAG:69 & 99 \\
\hline BL105A_0406 & DUF4012 & 1730 & $\begin{array}{l}\text { Auxiliary protein for envelope protein } \\
\text { Late cornified envelope protein } 3 C\end{array}$ & WP_008783638 & $\begin{array}{l}\text { Bifidobacterium sp.12 } 1 \\
\text { 47BFAA }\end{array}$ & 97 \\
\hline BL105A_0407 & $w z z$ & 1460 & Chain length determinant protein & WP_007057839.1 & B. longum & 97 \\
\hline BL105A_0408 & $\operatorname{cps} A$ & 1154 & GTF family 1 & WP_023658085.1 & B. longum & 100 \\
\hline BL105A_0409 & $\operatorname{cps} B$ & 1295 & GTF & WP_041080238.1 & B. longum & 100 \\
\hline BL105A_0410 & $\operatorname{cps} C$ & 1151 & GTF & WP_008704446.1 & $\begin{array}{l}\text { Ruminococcus sp. } 5139 \\
\text { BFAA }\end{array}$ & 68 \\
\hline BL105A_0411 & cpsE & 1964 & Possible GTF & WP_009854068.1 & Streptococcus gallolyticus & 41 \\
\hline BL105A_0412 & $c p s F$ & 890 & GTF & WP_015131440.1 & Calothrix sp.PCC 7507 & 29 \\
\hline BL105A_0413 & $\operatorname{cps} G$ & 533 & Possible GTF & WP_009854068.1 & Streptococcus gallolyticus & 42 \\
\hline BL105A_0414 & $w z y$ & 797 & $\begin{array}{l}\text { Oligosaccharide repeat unit poly- } \\
\text { merase }\end{array}$ & WP_009854069 & Streptococcus gallolyticus & 34 \\
\hline BL105A_0415 & $\operatorname{cps} P$ & 1100 & Polysaccharide pyruvyl transferase & WP_004405434 & Vibrio nigripulchritudo & 26 \\
\hline BL105A_0416 & $w z x$ & 1460 & Flippase & CAl33492 & Streptococcus pneumonia & 41 \\
\hline BL105A_0417 & cpsO & 245 & $\begin{array}{l}\text { Maltose O-acetyltransferase domain } \\
\text { protein }\end{array}$ & WP_009621938.1 & Desulfosporosinus sp. OT & 59 \\
\hline BL105A_0418 & $\operatorname{lnt}$ & 834 & Integrase catalytic region & BAP83067.1 & B. longum & 100 \\
\hline BL105A_0419 & istB & 834 & $\begin{array}{l}\text { Transposase (IstB-like ATP-binding } \\
\text { protein) }\end{array}$ & BAP83067.1 & B. longum & \\
\hline BL105A_0420 & & 1494 & Integrase core domain & ALE36745.1 & B. longum & 100 \\
\hline BL105A_0421 & insE & 1549 & Transposase (integrase) & WP_042764841.1 & Streptococcus pyogenes & 99 \\
\hline BL105A_0422 & insE & 408 & Transposase & WP_047379062.1 & B. longum & \\
\hline BL105A_0423 & & 669 & Integrase catalytic region & WP_047379102.1 & B. longum & 97 \\
\hline BL105A_0424 & $r m / B r f b B$ & 1022 & dTDP-D-Glucose 4,6-dehydratase & WP_047379646.1 & B. longum & 98 \\
\hline BL105A_0425 & & 1272 & Hypothetical gene & WP_047379940.1 & B. longum & 99 \\
\hline BL105A_0426 & $\mathrm{rm} / \mathrm{CrfbC}$ & 1457 & $\begin{array}{l}\text { Possible dTDP-4-keto-6-deoxy-D- } \\
\text { glucose epimerase }\end{array}$ & WP_047379058.1 & B. longum & 94 \\
\hline BL105A_0427 & $r m \mid A r f b A$ & 899 & $\begin{array}{l}\text { Glucose-1-phosphate } \\
\text { thymidyl transferase }\end{array}$ & $\begin{array}{l}\text { Glucose-1-phosphate } \\
\text { thymidyly } 1 \text { transferase }\end{array}$ & B. longum & 99 \\
\hline
\end{tabular}

longum GTF family 1 protein. The following four putative GTF genes, BL105A_0410 to BL105A_0413, have amino acid homologies ranging from 68 to $29 \%$ with GTF genes of Ruminococcus sp., Streptococcus gallolyticus, and Calothrix sp. (Table 1) and probably encode the GTF of the remaining sugars of the EPS subunit in an ordered and glycosidic-linkage dependent fashion.

The putative eps 3 operon possesses BL105A_0414 and BL105A_0416 genes that encode for proteins that have homology to proteins involved in the polymerization and transport of repeated oligosaccharide units across the cytoplasmic membrane. The protein encoded by the BL105A_0414 gene displays 34\% identity with WP_009854069 from S. gallolyticus (Table 1), which is annotated as the oligosaccharide repeat unit polymerase Wzy. The BL105A_0416 gene displays 41\% identity with
CAI33492 from S. pneumonia, which is interpreted as the flippase Wzx (Table 1). Polysaccharide subunits are flipped across the cytoplasmic membrane by the Wzxtype exporter and polymerized into long polysaccharides by Wzy-type polymerase at the outer-side cellular membrane (Fig. 1) [47]. The lower homology of the Wzx-type exporter and Wzy-type polymerase compared to the more conserved Wzd/Wze and Wzb homologs were also observed in the genome of L. rhamnosus GG [67]. Predicted results from SOSUI software show that the proteins of the genes BL105A_0405 to BL105A_0407 and $B L 105 A \_0414$ to $B L 105 A \_0416$ are all the transmembrane proteins (Additional file 1: Figure S2). However, the lower homology of putative Wzx and Wzy proteins is predicted to be due to these transmembrane proteins being specific for the associated EPS repeated unit of $B$. 
longum 105-A. ABC-transporter genes have also been reported to be involved in the transport of EPS oligosaccharide units across the cytoplasmic membrane in Bifidobacterium species $[35,58]$, but we did not find any genes in this B. longum 105-A putative EPS-encoding locus that had homology with known $\mathrm{ABC}$-transporter genes.

Also, putative eps3 operon contains BL105A_0415 and $B L 105 A \_0417$. The protein encoded by the BL105A_0415 gene has 26\% identity with WP_004405434 from Vibrio nigripulchritudo (Table 1), which annotated as a polysaccharide pyruvyltransferase. The protein encoded by the BL105A_0417 gene has $59 \%$ identity with WP_009621938.1 from Desulfosporosinus sp. and was annotated as a maltose $O$-acetyltransferase. Pyruvyltransferases and acetyltransferase are thought to be involved in the modification of CPS/EPS, and should modulate physicochemical and biological properties.

Previous studies have shown that L-rhamnose is a component of Bifidobacterial cell walls [68]. In this study, we have identified three gene analogs known to be involved in the dTDP-rhamnose biosynthesis pathway located in the EPS gene cluster (Fig. 1). The genes BL105A_0424, BL105A_0426 and BL105A_0427 encode putative dTDP-D-glucose 4, 6-dehydratase, possible dTDP-4-keto-6-deoxy-D-glucose epimerase and dTDPglucose pyrophosphorylase, respectively (Fig. 1; Table 1). Similarly, Lebeer et al. [64] also found putative genes for dTDP-rhamnose biosynthesis located in the EPS cluster of $L$. rhamnosus GG.

We observed that in the identified putative B. longum 105-A EPS gene cluster, the genes which encode the putative priming-glycosyltransferase, envelope protein, chain length determinant protein, first two glycosyltransferases, rhamnose biosynthesis precursors, and tyrosine kinase (BL105A_0405-BL105A_0409, BL105A_0424$\left.B L 105 A \_0427\right)$ are conserved in other Bifidobacterium strains, but other glycosyltransferases, polymerase, pyruvyltransferase, flippase, and acetyltransferase genes (BL105A_0410-BL105A_0417) are specific for the associated EPS repeating unit (36-37), as reflected by their lower level of similarity to other orthologs (Table 1), according to the reported mechanism of EPS production in S. pneumoniae and L. rhamnosus [64, 69].

\section{Morphology of $B$. longum 105-A $\Delta$ cpsD mutant}

The priming-glycosyltransferase is predicted to be a necessary control point of CPS/EPS production. We hypothesized that the knockout of the gene BL105A_0405, a homolog of $c p s D$, could affect CPS/EPS production. To demonstrate this hypothesis, we knocked out the putative priming-transferase $c p s D$ gene (BL105A_0405) in $B$. longum 105-A. The deletion of cpsD from $B$. longum 105-A was confirmed by PCR and DNA sequencing.
In contrast to the wild-type strain, which had a typically smooth and glossy colony appearance when grown on MRS plates, the mutant colony was less smooth and glossy. The growth curves of the wildtype strain and the B. longum 105-A $\Delta c p s D$ mutant strain were similar (Additional file 2: Figure S4A). However, the cells of the $\Delta c p s D$ mutant were found to quickly sediment after the stationary phase in liquid medium (Additional file 2: Figure S4B, C), while the wild-type strain remained in suspension (Additional file 2: Figure S4B, C).

To confirm EPS production of both the wild-type strain and the $\triangle c p s D$ mutant, we analyzed the supernatant from late exponential phase cultures by HPLC. The monosaccharides from the hydrolysate of wild-type B. longum 105-A EPS consisted of the monosaccharides that should be galacturonic acid, glucose (Glc), and galactose (Gal). Although two more monosaccharides were detected in the hydrolysate (Peaks 3 and 4 in Additional file 3: Figure S3A), we could not find out the details. According to Altmann et al. [70], the unusual sugar $\mathrm{L}-6$-deoxyL-talose ( $\mathrm{L}-6 \mathrm{dTal})$ was found in the EPS produced by the B. longum subsp. longum $35624^{\mathrm{TM}}$ strain. Therefore, there is possibility that either Peak 3 or 4 in Additional file 3: Figure S3A, which was in the hydrolysate of the EPS from wild-type B. longum 105-A, was $\mathrm{L}-6 \mathrm{dTal}$. The monosaccharides from the hydrolysate of the $\Delta c p s D$ mutant showed a marked decrease of Peak 3 and the disappearance of Peak 4 as compared to wildtype (Additional file 3: Figure S3A). On the other hand, the ratio of Glc/Gal was 1:1.48 in the EPS produced by the wild-type, while the ratio was $1: 1.76$ in the EPS produced by its $\triangle c p s D$ mutant (Additional file 3: Figure S3B). Furthermore, the EPS of the mutant contained polysaccharides with higher average molecular weight $(500 \mathrm{kDa})$ than the wild-type $(200 \mathrm{kDa})$ (Additional file 3: Figure $\mathrm{S} 3 \mathrm{C}$ ).

To determine the presence of an outer cell surface polysaccharide layer, presumed to be the capsule consisting of surface EPS, we performed India ink staining to visualize the polysaccharide layer. The polysaccharides in the capsule displace the colloidal carbon particles of the ink and appear as a clear halo around the microorganism [71]. It showed that a polysaccharide layer is absent in the $\Delta c p s D$ mutant bacterium, while a clear 'polysaccharide' halo could be observed in the wild-type bacterium (Fig. 2a). Our observation using a transmission electron microscope indicated that the wild-type $B$. longum 105-A is surrounded by a dense capsule layer (ca. $0.2 \mu \mathrm{m}$ ), while the $B$. longum 105-A $\Delta c p s D$ mutant has lost the CPS layer, however, an enormous number of fimbriae-like appendages were found instead of the capsule (Fig. 2b). 

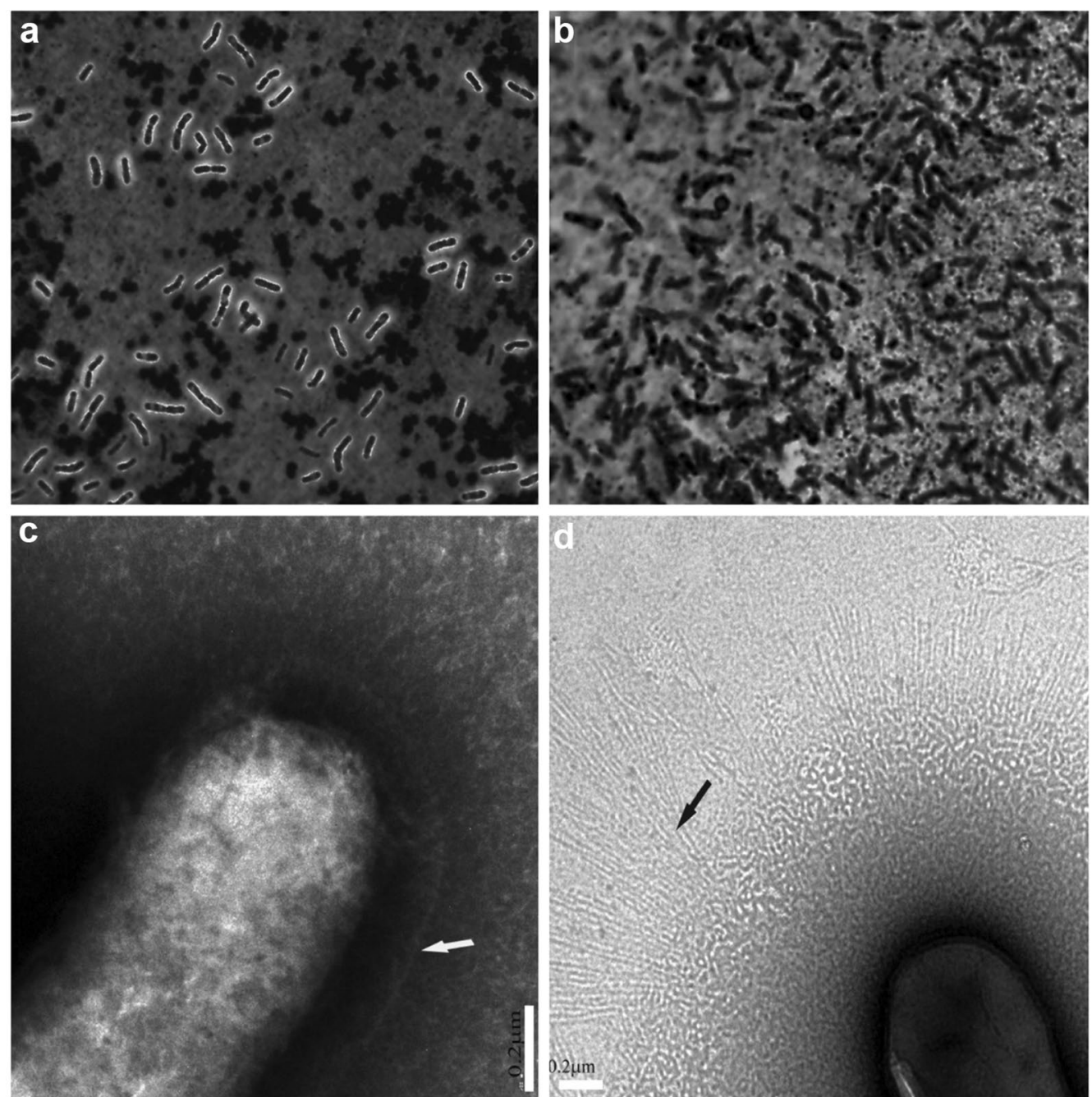

Fig. 2 Light microscope images of B. longum 105-A and $\triangle c p s D$ mutant. India ink staining, the polysaccharide capsule appears as a clear halo around the microorganism in the wild-type B. longum 105-A (a), while this layer not present in its $\triangle c p s D$ mutant $(\mathbf{b})$. TEM images with negative staining. Wild-type expressing ca. 0.2- $\mu \mathrm{m}$-thick CPS layer (c, and white arrow), while the mutant did not possess the CPS but expressing long and dense fimbriae (d, and black arrow). White bars $0.2 \mu \mathrm{m}$

\section{qPCR analysis of EPS gene cluster}

In this point, the protein level verification, such as anti-CpsD antibody detection method, was unavailable; thus, an alternative approach was used to confirm the deletion of the $c p s D$ gene and the influence of this deletion on downstream genes is shown in the qPCR analysis (Table 1). The expression of the cpsD gene was completely undetectable in the $\triangle c p s D$ mutant (Fig. 3). Thus, the deletion of the cpsD gene in the $\Delta c p s D$ mutant was also proven by qPCR. Expression of the late cornified envelope protein (BL105A_0406) gene, which is adjacent to the $c p s D$ gene, was also undetectable in the $\triangle c p s D$ mutant. Interestingly, the expression of the BL105A_0408 gene, encoding a GTF, and of the BL105A_0414 gene (polymerase), which reside downstream of the $c p s D$ gene in the eps1 operon, was found to be significantly decreased, by approximately $80 \%(P<0.001)$, in the $\triangle c p s D$ mutant. Furthermore, expression of gene $B L 105 A$ 0424 gene (dTDP-D-glucose 4,6-dehydratase) that resides in eps 4 operon was also decreased $(P<0.001)$ to about $20 \%$ (Fig. 3 ) in the $\Delta c p s D$ mutant compared to the wild-type strain expression.

\section{Tolerance to in vitro simulated gastrointestinal transit conditions}

We compared the ability of the wild-type and the $B$. longum 105-A $\Delta c p s D$ mutant to survive in simulated gastrointestinal transit conditions. We found that a change from $\mathrm{pH}$ 6.5-5.0 significantly decreased the survival rate from 100 to $30 \%$ for the wild-type, and to $19 \%$ for $\Delta c p s D$ 


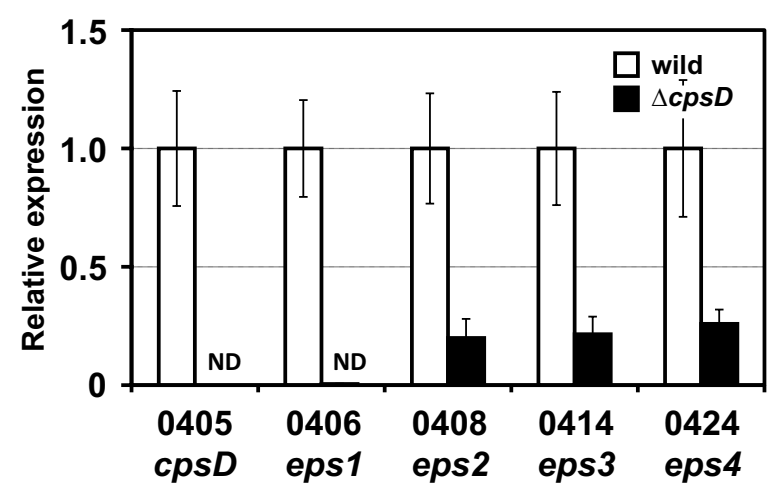

Fig. 3 qPCR to confirm the deletion of $\operatorname{cps} D$ and its influence on downstream genes. Relative expression of wild-type B. longum 105-A (white) against $B$. longum 105-A $\triangle c p s D$ (black) of BL105A_0405 (cpsD), BL105A_0406, BL105A_0408, BL105A_0414, and BL105A_0424 (as indicated numbers) were analyzed by qPCR using the $2^{-\triangle C T}$ method. The rnaP gene was used as housekeeping control to normalize the data. In comparison to the wild-type B. longum 105-A, the expression of BL105A_0405 (cpsD) gene was undetectable in the $\triangle c p s D$ mutant. The downstream gene BL105A_0406, was significantly decreased by approximately $0.46 \%(P<0.001)$ in the $\triangle c p s D$ mutant. The expression of genes, BL105A_0408, BL105A_0414, and BL105A_0424, were also decreased to $20 \%(P<0.01)$. Temporal operon name also indicated below. ND not detected

mutant strains (Fig. 4a). At a lower $\mathrm{pH}$ range, while the survival rate of the wild-type strain remained at approximately $20 \%$, there was a significantly lower survival rate for the $\Delta c p s D$ mutant over a range of $\mathrm{pH} 4.0-3.5$.

The pre-incubation treatment at $\mathrm{pH} 4.5$ for $120 \mathrm{~min}$ significantly increased the survival rate of the wild-type strain challenged at pH 3.5 from 18 to $30 \%$ (Fig. 4b). Interestingly, with the $\Delta c p s D$ mutant strain that is lacking CPS, the pre-incubation acid treatment had no adaptation effect on the survival of rate of the bacteria challenged at $\mathrm{pH} 3.5$.

We then investigated the protective role of B. longum 105-A CPS/EPS to exposure to bile salts. Incubation of wild-type B. longum 105-A in bile salt, up to a concentration of $0.2 \%$, increased the overall colony survival rate, then it was decreased to $20 \%$ at a bile concentration of $0.3 \%$, whereas the $\Delta c p s D$ mutant exhibited a significantly decreased survival rate with $0.1-0.3 \%$ bile salt (Fig. $4 \mathrm{c}$ ).

\section{Binding to Caco-2 and internalization by macrophages}

Cell surface CPS is an important bacterial adhesion factor, which assists inter-bacterial binding for biofilm formation, as well as adhesion to both inert and eukaryotic cellular surfaces [31, 72, 73]. In this study, we analyzed the role of CPS in B. longum 105-A binding on polarized intestinal epithelial-like cells Caco-2. To achieve this, we challenged the cells with a multiplicity of infections $(\mathrm{MOI})=100$ from the B. longum 105-A wild-type and $\triangle c p s D$ mutant. The attached bacteria were determined after $1 \mathrm{~h}$ of incubation using Giemsa staining and a phase contrast microscope.

We found that the CPS was demonstrated to have a suppressive effect on the binding of the B. longum 105-A to the Caco-2 epithelial cell line. The wild-type bacteria did not bind to the monolayer cultured Caco-2 cells (Fig. 5a). However, its CPS mutant was able to bind (Fig. 5b), and the average number of adherent bacteria per nucleus, $\pm \mathrm{SD}$, was $7.8 \pm 2.3$ (Fig. $5 \mathrm{~b}$ ).

In addition, CPS is thought to play an essential role in interaction with non-specific immune cells. CPS has been implicated in the prevention of phagocytosis by phagocytic cells by Lactococcus lactis [74]. In the present study, optical microscopy using Giemsa stain was carried out to determine the role of CPS in interaction with murine macrophage cell line, RAW 364.7. The wild-type B. longum 105-A was shown to completely avoid the phagocytosis by murine macrophage (Fig. 5c). However, its $\Delta c p s D$ mutant failed to evade internalization with this phagocytic cell, and a mean number of phagocytosed B. longum 105-A $\Delta c p s D$ per macrophage was $4.1 \pm 1.4$ (Fig. $5 \mathrm{~d}$ ).

\section{Discussion}

The role of CPS in probiotic activities has been studied recently in Lactobacillus and Lactococcus probiotics [64, 74 . However, little is known about the function of the CPS/EPS in Bifidobacteria. In this study, we identified the EPS gene localization in B. longum 105-A and characterized the function of CPS/EPS in the attachment of the bacteria to intestinal epithelial cells and interaction with macrophage.

During the investigation of B. longum 105-A, we identified a gene cluster, which consisted of continuous 6 glycosyltransferases and one priming glycosyltransferase gene (Fig. 1). Among them, four genes are not found in other Bifidobacteria (Table 1). The putative genes involved in CPS/EPS biogenesis were also found in the flanking region including priming glycosyltransferase, cpsD (undecaprenyl-phosphate galactose phosphotransferase), oligosaccharide repeat unit polymerase, and flippase which was investigated in L. rhamnosus GG and found in some Streptococci [64]. The putative rhamnose biosynthesis genes $r m l A, r m l B, r m l D$, and putative pyruvyl transferase (cpsP) were also found in the downstream (Table 1). These findings suggest that B. longum 105-A produces CPS and/or EPS by this gene cluster, which is the likely polymer of a hepta-oligosaccharide unit. We assumed that this gene cluster was responsible for the CPS/EPS of this strain. 

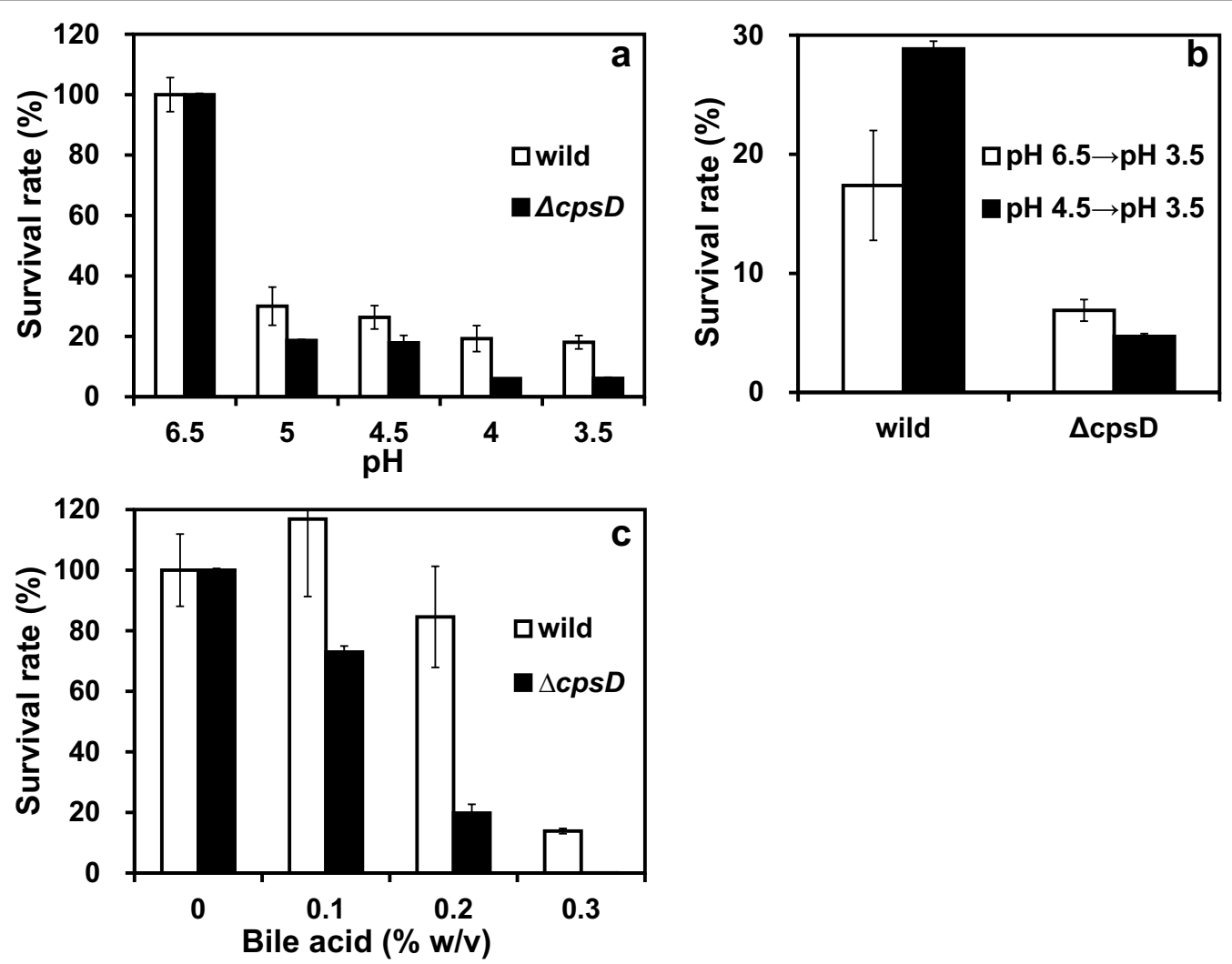

Fig. 4 Effects CPS on the bacterial resistance to bile salts and acid. a Survival rate of B. longum 105-A (white) and B. longum 105-A $\triangle c p s D$ (black) in MRS broth, which is adjusted to indicated $\mathrm{pH}$. b Adaptation by low pH. Cells were pre-incubated at $37^{\circ} \mathrm{C}$, for $2 \mathrm{~h}$ in MRS (pH 6.5; white) or pH 4.5 (black), then transferred to the same medium but pH 3.5 incubate for 2 h. B. longum 105-A (left) and B. longum 105-A $\triangle c p s D$ (right). c Survival rate of B. longum 105-A (white) and B. longum 105-A $\triangle c p s D$ (black) in MRS broth contained bile acid, $0-0.3 \%(\mathrm{w} / \mathrm{v})$

The bacteria use several strategies to adapt to their environment. One of the most important mechanisms is the cascade of long-term horizontal gene transfer between bacteria. To achieve this, the bacteria can acquire or lose genes through receiving plasmids, genomic islands, and bacteriophages. These methods can generate smaller insertion sequences (IS), transposons and integrons that are associated with the integrases and transposases which are required for the generation of gene losses and the acquisition of new genes in the bacterial genome [75].

The gene cluster of B. longum 105-A is surrounded by multiple genes encoding putative transposase genes (BL105A_0403, BL105A 0421 to BL105A 0422). Hidalgo-Cantabrana et al. [17] noted that the presence of genes encoding transposases and insertion sequences is a common feature found in the EPS clusters of both lactic acid bacteria species and Bifidobacteria. Moreover, this region shows low nucleotide homology to other Bifidobacteria. It suggests that this gene set has been gained from other bacteria by several horizontal gene transfer events in the recent evolution of B. longum 105-A.
Interestingly, there are three putative integrase genes in this region. It is reported that the genome sequences of $B$. longum NCC2705 and DJO10A harbor the mobile integrase cassette (MIC) structures, consisting of three contiguous integrase genes flanked by an inverted repeat and a palindrome structure sandwiched by two $I S$ elements. During a pure culture of B. longum DJO10A of over 1000 generations, a MIC element was found to be deleted from the genome along with $\sim 50 \mathrm{~kb}$ of the sequence [51, 76, 77]. This EPS gene cluster of B. longum 105-A also harbors the three putative integrase genes and multiple transposase genes. It suggested that the active MIC structure exists in this EPS gene cluster, and deletion of this cluster may be caused during a pure culture of $B$. longum 105-A by prolonged culture.

The culture morphology of the bacteria on the plate indicated that the wild-type strain had a smooth and glossy colony appearance when grown on MRS plates, while the mutant colony was less shiny. Dertli et al. [47] reported that a single nucleotide change in the epsC gene of L. johnsonii FI9785 also caused a morphological change from a rough to a smooth colony. 

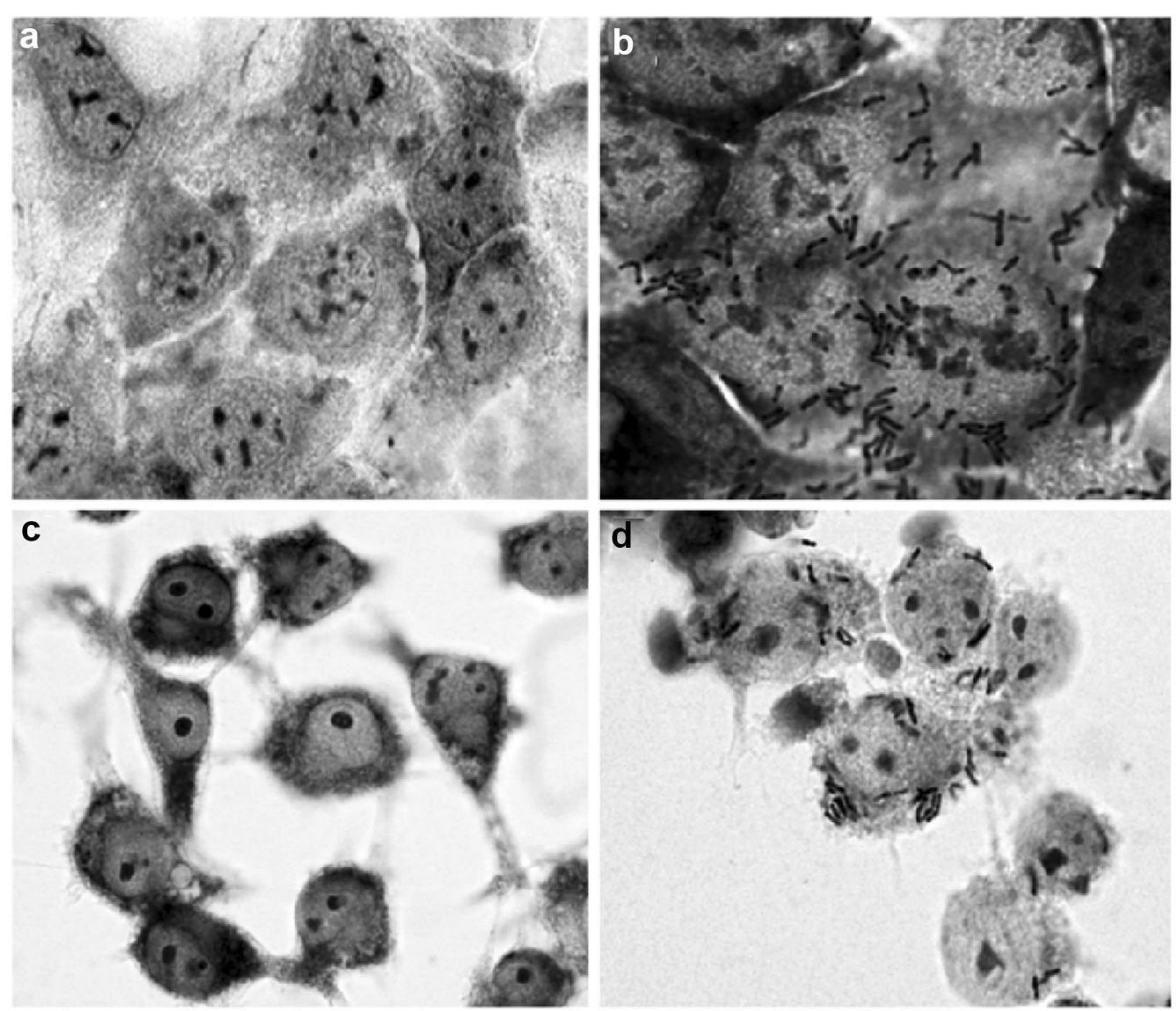

Fig. 5 Bifidobacterium longum 105-A adherence to Caco-2 cells and phagocytosis by murine macrophage. 70\% confluent monolayers of Caco-2 cells were challenged with B. longum 105-A (a) and its $\Delta c p s D$ mutant (b) at $\mathrm{MOI}=100$, then determined by phase contrast microscopy. No adherent bacterial cell was observed in the wild-type (a) but a lot of adherent bacteria were observed in $\triangle c p s D$ mutant (b). The number of attached $\triangle c p s D$ cells per Caco-2 cell was $7.8 \pm 2.3$ (nucleus \pm SD). Three slides for each bacterial strain and at least 20 fields per slide were counted. B. longum 105-A phagocytosis by murine macrophage. Semi-confluent RAW 264.7 murine macrophage was challenged with B. longum 105-A (c) and its $\triangle c p s D$ mutant (d) for $30 \mathrm{~min}$. Then, the medium was removed and the cells were washed 5 times with PBS and replace to DMEM containing gentamycin $(100 \mathrm{\mu g} / \mathrm{ml})$ and incubate for another $1 \mathrm{~h}$. The coverslips were then washed 3 times with PBS and the cells were fixed with methanol and stained with Giemsa stain. In the wild-type, no bacterial cell was observed both inside and outside of macrophage cell (c) but $\Delta c p s D$ mutant was internalized into Raw 264.7 murine macrophage cells $(\mathbf{d})$. The number of internalized bacterial ce1 ls per macrophage cell was $4.1 \pm 1$

The $\Delta c p s D$ mutant was quickly sediment after the stationary phase in the liquid medium due to loss of the capsule. The capsule removal allowed bacterial aggregation and facilitated the sedimentation in the liquid media (Additional file 2: Figure S4B, C), but the wild-type strain continued in suspension for a long period. Fanning et al. also observed that $B$. breve UCC2003 EPS negative mutants were found to sediment during growth in the liquid medium [31].

In this study, we found that although the $\operatorname{cps} D$ was removed from B. longum 105-A, the EPS was still produced by the mutant, but some monosaccharides had a reduced amount. The data obtained from India ink staining and TEM postulated that these changes in the polysaccharide structure lead to changes in the morphology of the $\Delta c p s D$ mutant that are different from the wildtype (Fig. 2). Previous investigations have demonstrated that monosaccharide L-6-deoxy-talose (L-6dTal) plays an important role in capsule formation [78]. As there is much possibility that the monosaccharide, which had a reduced amount, is L-6dTal, this agreed with our results, and we suggested that the absence of the capsule in the $\operatorname{csp} D$ mutant was due to the decrease of some monosaccharides, such as $\mathrm{L}-6 \mathrm{dTal}$, in its EPS secretion. It was documented that the appearance of adhesion factors, such as fimbriae and galactan, was correlated with changes in EPS structure and increased the cell-cell binding. The appearance of fimbriae-like appendages after removing the CPS is reported in L. rhamnosus GG [64], which agreed with our TEM analysis as the fimbriae-like 
structure was observed in the $\triangle c p s D$ mutant. Taken together, the data suggest that CPS inhibit fimbriae expression by the wild-type B. longum 105-A. Our qPCR finding indicated that the expression of the BL105A_0406 gene was not detected in the mutant. Expression of the genes, which localized downstream of the cpsD gene, were found to be reduced. It suggested that the $c p s D$ gene regulates the expression of other genes in the clusters [79].

After oral intake by the host, Bifidobacteria have to reach the colon, the suitable niche, and deal with the stresses throughout the gastrointestinal tract including the low-pH environment of the stomach and bile salts excreted in the duodenum $[80,81]$. The $\mathrm{pH}$ of gastric acid is 1.5-3.5 in the human stomach lumen and gradually increases in the small intestine from $\mathrm{pH} 6$ to about $\mathrm{pH} 7.4$ in the terminal ileum. The $\mathrm{pH}$ drops to about 5.7 in the caecum but again gradually increases, reaching $\mathrm{pH}$ 6.7 in the rectum [82].

In general, the viability of Bifidobacteria at gastric juice $\mathrm{pH}$ values is known to be low [83], showing survival rates ranging from less than 1-30\% depending on the experimental conditions, species, and strains. A mechanism for an adaptive response to low-pH exposure has been reported in lactic acid bacteria species [84]. However, there are only a few reports of acid tolerance induction of Bifidobacteria [83]. Our results suggest that preincubation of the wild-type B. longum strain at $\mathrm{pH} 4.5$ significantly increased the survival rate of the wild-type strain challenged at pH 3.5 (Fig. 4b). These observations suggested that the pre-incubation treatment induced an adaptive $\mathrm{pH}$ response in the wild-type strain. On the other hand, pre-incubation acid treatment of the $\Delta c p s D$ mutant strain that is lacking CPS showed no significant effect on the survival of rate of these bacteria tested at a pH 3.5 (Fig. 4b), indicating that the mutant could not adapt to the low $\mathrm{pH}$ in vitro.

Bile salt is a detergent-like biological compound, which is stored in the gallbladder and flows to the duodenum that disrupts the structure of bacterial cell membranes. In the intestine, its concentration is retained in the range between 0.05 and $2 \%$ under the physiological conditions $[85,86]$. The tolerance to bile salt is a necessary property for probiotic bacteria to survive transit through the duodenum [85]. Bile salt affects both the cell and colony morphology [87]; it shows that gut bacteria deal with it in several ways [87]. In addition to the active efflux and hydrolysis of bile salts, the changes in the architecture/ composition of the capsular polysaccharide layer appear to be a prominent bile tolerance mechanisms in Bifidobacteria [85, 88, 89]. A correlation between Bifidobacteria EPS production and bile tolerance has been shown to exist in both in vitro and in vivo $[31,62]$. The result of our resistance assays revealed that production of CPS by $B$. longum 105-A was shown to provide resistance to stress environmental conditions. Although the stress conditions in the colon are comparatively mild, we presume that EPS is needed to tolerate the strict stress conditions of the stomach and duodenum. This finding suggested that CPS/EPS exocellular polymer layers act as a protective coat against environmental conditions (Fig. 4c) [90, 91].

Attachment to epithelial cells by probiotic bacteria is a crucial event that allows for the colonization of the host intestinal tract. It allows the microbiota to multiply on the gut surface and perform its function of preventing of pathogenic bacteria from attaching. We used the human intestinal Caco-2 epithelial cell line [92, 93]. CPS is the major bacteria factor that has been implicated in the binding of many probiotics to the intestinal epithelium, and it was shown to play a role in $B$. breve colonization to mouse intestines [31]. We hypothesized that the presence of CPS inhibits expression of bacterial factors, such as fimbriae that might be involved in bacterial cell attachment. We verified this hypothesis by challenging the cultured Caco-2 cells with B. longum 105-A and its $\triangle c p s D$ mutant. This study demonstrates that the wildtype B. longum 105-A did not bind to the epithelial cells in comparison to extensive binding by its $c p s D$ mutant (Fig. 5a, b). These results were completely different from that demonstrated by Fanning et al. 2012, which showed a significant role of CPS in the initial binding of $B$. breve in the initial colonization of the mouse gut. We explain that because of the CPS of B. longum 105-A is the completely has a different structure from that of $B$. breve. Previous studies have shown that deletion of the gene responsible for the production of long galactoserich EPS in of L. rhamnosus GG resulted in an increased adhesion to Caco-2 cells $[64,94,95]$. The polysaccharides derived from $B$. longum 105-A showed unique and complete composition in comparison to other different probiotics bacteria. The CPS of B. longum 105-A might act as a barrier against colonization of this bacterial strain by covering or suppressing the expression of the organelles that help the bacteria to bind, such as fimbriae (Fig. 2c, d).

In Gram-positive pathogens, the CPS are considered to be the virulence factor that prevents phagocytosis. We performed phagocytosis experiments to assess the impact of B. longum 105-A's CPS on preventing phagocytosis by macrophages. Our results showed that the B. longum 105-A CPS confers resistance to B. longum 105-A against being internalized by murine macrophages (Fig. 5c, d). The susceptibility to phagocytosis of CPSnegative mutant strains indicates that the CPS mutant can help in the activation of host immunity [96]. 
In summary, the results of this study identified the CPS/EPS gene cluster in B. longum 105-A. The CPS plays key roles in the survival of $B$. longum in vitro by conferring resistance to adverse physiological conditions such as low $\mathrm{pH}$ and bile salts. We also demonstrate that CPS production and fimbriae formation are negatively correlated. This work has confirmed that the CPS plays a crucial role in B. longum 105-A interaction with host cells. We speculate that $\mathrm{L}-6 \mathrm{dTal}$ is the predicted monosaccharide that plays a role in capsule formation. Future work should confirm the structure of B. longum 105-A CPS in relation to its function.

In this work, we have demonstrated that the $\Delta c p s D$ mutant of B. longum 105-A interacts better with the eukaryotic cells than the wild-type bacteria in vitro. In the future, further investigations, including in vivo study, should be carried out to examine its ability to survive in the animal host and to its role in immune modulation and preventing the infection with pathogenic microorganisms.

\section{Methods}

Bacterial strains and culture conditions

Bifidobacterium longum 105-A was used as the host strain. Escherichia coli TOP10 (Thermo Fisher Scientific, Waltham, MA, USA) was used as the cloning host for plasmid construction. B. longum was grown under anaerobic conditions at $37^{\circ} \mathrm{C}$ in MRS broth (Becton, Dickinson and Company, Franklin Lakes, NJ, USA). E. coli were grown on LB medium (10 g tryptone, $5 \mathrm{~g}$ yeast extract and $5 \mathrm{~g} \mathrm{NaCl} / \mathrm{L}$ ) at $37^{\circ} \mathrm{C}$. For plate culture, $1.5 \%$ agar was added to the medium before autoclaving. Chloramphenicol $(25 \mu \mathrm{g} / \mathrm{ml})$, spectinomycin $(75 \mu \mathrm{g} / \mathrm{ml})$, or ampicillin $(100 \mu \mathrm{g} / \mathrm{ml})$ was supplemented as necessary. The growth curve of Bifidobacterium was recorded using Bio-plotter OT-201 (Oriental Instruments, Sagamihara, Japan).

\section{In silico analysis}

The genome sequence of B. longum 105-A was previously reported [61] (Accession Number: AP014658). Blast search [97] was performed using the National Centre for Biotechnology Information website (http://blast. ncbi.nlm.nih.gov/Blast.cgi). Sequence analysis was executed using CLC Genomics Workbench (Qiagen, Hilden, Germany) and motif searches were performed using the EMBL-EBI website (http://www.ebi.ac.uk/services). The hydrophobicity plot and transmembrane region predictions were carried out by SOSUI (http://harrier.nagahama-i-bio.ac.jp/sosui/) [98].

\section{Molecular techniques}

Genomic DNA of B. longum 105-A and its derivatives were extracted by using an ISOIL for Beads Beating Kit
(Nippon Gene Co., Ltd, Tokyo, Japan). Plasmid extractions from $E$. coli strains were performed using a QIAprep Spin Miniprep Kit (Qiagen). DNA digestion with restriction enzymes was performed according to the manufacturer's protocol (Takara Bio Inc., Kusatsu, Japan). DNA sequencing of plasmid and genomic DNA was performed on an ABI 3130xl DNA sequencer using a BigDye Terminator ver. 3.1 Cycle Sequencing Kit (Thermo Fisher Scientific).

\section{PCR}

The primer sequences used in this study for generating plasmids or confirming the deletion of target genes are described in Additional file 4: Table S1. The primers were designed by In Silico Molecular Cloning (IMC, In Silico Biology, Inc., Yokohama, Japan), plasmid Editor Software or Oligo Primer Analysis Software ver.7 (Molecular Biology Insights, Colorado Springs, CO, USA). GoTaq DNA polymerase (Promega, Fitchburg, WI, USA) was used for colony-direct PCR of E. coli transformants, and KOD-plus-Neo DNA polymerase (Toyobo Co. Ltd., Osaka, Japan) was used for cloning of B. longum genomic DNA, as described by the manufacturer's protocol. The PCR products were analyzed by $1 \%(\mathrm{w} / \mathrm{v})$ agarose gel electrophoresis with TAE buffer. For cloning, the target fragments of the PCR products were extracted from the gel using a NucleoSpin kit (MACHEREY-NAGEL, Düren, Germany). The PCR conditions using KOD-plusNeo DNA polymerase were as follows: $94{ }^{\circ} \mathrm{C}$ for $2 \mathrm{~min}$, 25 cycles of $98{ }^{\circ} \mathrm{C}$ for $10 \mathrm{~s}, 57^{\circ} \mathrm{C}$ or $60{ }^{\circ} \mathrm{C}$ for $30 \mathrm{~s}$, and $68{ }^{\circ} \mathrm{C}$ for $1 \mathrm{~min}$. The PCR conditions using GoTaq DNA polymerase were as follows: $95^{\circ} \mathrm{C}$ for $2 \mathrm{~min}, 30$ cycles of $\left(95^{\circ} \mathrm{C}\right.$ for $1 \mathrm{~min}, 57^{\circ} \mathrm{C}$ or $60{ }^{\circ} \mathrm{C}$ for $1 \mathrm{~min}$, and $72{ }^{\circ} \mathrm{C}$ for $1 \mathrm{~min}$ ), then $72{ }^{\circ} \mathrm{C}$ for $10 \mathrm{~min}$.

\section{Plasmid construction}

The plasmid for the gene deletion, pKO403- $\Delta$ cpsD (Additional file 5: Figure S1), was constructed as follows by using the Golden Gate Technique [99]. The PCR primers were designed according to the putative cpsD gene (BL105A_0405) of B. longum 105-A genome sequence. To obtain the gene deletion DNA fragments, about $1.0 \mathrm{~kb}$ up- and downstream fragments of BL105A_0405 were amplified by PCR as summarized in Additional file 4: Table S1. To construct the gene deletion plasmid, we used the modified pUC19 and pKO403 Bifidobacterium-E. coli shuttle vector plasmids [55]. Both plasmids carry lac $Z$ to facilitate blue-white selection (pUC19-SapI and pKO403lacZ). The pUC-SapI plasmid was digested using Bsp68I, and the produced DNA fragments were connected to the Bsp68I-digested pUC-SapI by ligation conducted at $16{ }^{\circ} \mathrm{C}$ for $30 \mathrm{~min}$. The ligated plasmids were introduced into $E$. coli TOP10 and confirmed by colony PCR to obtain the 
correct constructs. These up- and down-stream plasmids and pUC-Sp were cloned into a pKO403-lacZ using SapI and then transferred into E. coli TOP10 and confirmed by colony-direct PCR. Obtained plasmid was designated as the $\mathrm{pKO} 403-\Delta c p s D$ plasmid.

\section{Gene knockout of target gene}

Bifidobacterium longum 105-A cells were transformed with pKO403- $\Delta c p s D$ by electroporation [60]. After electroporation, cells were spread and cultured on MRS plates containing $\mathrm{Sp}$. The transformants were selected and cultured in MRS liquid medium containing Sp. The bacterial culture was serially diluted and spread on MRS plates containing $\mathrm{Sp}$ and was incubated at $42{ }^{\circ} \mathrm{C}$ for 3 days. The obtained colonies were duplicated onto Spand $\mathrm{Cm}$-MRS plates and incubated at $37{ }^{\circ} \mathrm{C}$ for 2 days. Sp-resistant $\left(\mathrm{Sp}^{\mathrm{r}}\right)$ and $\mathrm{Cm}$-sensitive $\left(\mathrm{Cm}^{\mathrm{s}}\right)$ colonies were selected as gene-knockout candidates and analyzed by PCR and DNA sequencing (Additional file 5: Figure S1).

\section{EPS characterization}

The supernatant from late exponential phase cultures of $B$. longum 105-A wild-type or its $\Delta c p s D$ mutant was filtrated using a $0.45-\mu \mathrm{m}$ filter. The polysaccharide of culture supernatant was precipitated using 2 volume of $99.5 \%$ ethanol for an overnight at $4{ }^{\circ} \mathrm{C}$. The ethanol-suspended polysaccharides were centrifuged at $7000 \mathrm{rpm}$ for $30 \mathrm{~min}$. The pellet was dried out at $55{ }^{\circ} \mathrm{C}$ for $1 \mathrm{~h}$ and resuspended in water. The obtained polysaccharides were then acid hydrolyzed with $4 \mathrm{M}$ trifluoroacetic acid at $100{ }^{\circ} \mathrm{C}$ for $3 \mathrm{~h}$. The chromatography of monosaccharide analysis was conducted with an Asahipak GS-220 HQ column $(300 \times 7.5 \mathrm{~mm}$, Showa Denko, Tokyo, Japan). The EPS was eluted in water at a flow rate of $0.4 \mathrm{ml} / \mathrm{min}$ at $30{ }^{\circ} \mathrm{C}$, followed by post-column reaction with arginine/boric acid, and monitored by a fluorescent detector (Excitation: $331 \mathrm{~nm}$, Emission: $383 \mathrm{~nm}$ ). The chromatography of monosaccharide analysis to separate the glucose and galactose was performed with a YMC-Pack NH2 column $(250 \times 4.6 \mathrm{~mm}$, YMC Co., LTD., Tokyo, Japan $)$. The EPS was eluted with $25 \%$ water and $75 \% \mathrm{CH}_{3} \mathrm{CN}$, at a flow rate of $0.5 \mathrm{ml} / \mathrm{min}$ at $50{ }^{\circ} \mathrm{C}$ with a fluorescent detection as above. For molecular weight analysis, the SUGAR KS-804 column $(300 \times 8.0 \mathrm{~mm}$, Showa Denko, Tokyo, Japan) was used with a flow rate of $1.0 \mathrm{ml} / \mathrm{min}$ using a refractive index detector at $50{ }^{\circ} \mathrm{C}$. The experiments were performed in duplicate.

\section{India ink staining}

Twenty microliters of the bacterial culture was mixed with one drop of India ink on microscope slide glass, left to dry, then stained with crystal violet for $1 \mathrm{~min}$, then rinsed gently with water, and dried [71]. The slides were examined using bright-field illumination on a microscope (BX-51, Olympus Corp., Japan).

\section{Transmission electron microscopy (TEM)}

For further identification of the morphology of $B$. longum 105-A wild-type and B. longum 105-A $\Delta c p s D$ mutant, we used the negative stain technique of TEM with phosphotungstic acid (PTA). Briefly, the bacteria were cultured overnight in MRS broth medium. Glow-discharged grids with a supported membrane (Cat. No. U1011, EM Japan Co. Ltd., Tokyo, Japan) were used to be covered by bacterial cells. $5 \mu \mathrm{l}$ of the bacterial culture was placed onto the grid and incubated for $60 \mathrm{~s}$, and then stained with $5 \mu \mathrm{l}$ of $2 \%$ PTA (pH 7.4) for $45 \mathrm{~s}$. The excess stain was drained using filter paper, and the grids were dried in a desiccator for $3 \mathrm{~h}$. The bacteria were observed with a TEM at $200 \mathrm{kV}$ (JEM 2100F, JEOL Ltd., Tokyo, Japan).

\section{Analysis of gene expression levels by qPCR}

For qPCR analysis, total RNA was extracted from $10 \mathrm{ml}$ logarithmic growth phase cultures $\left(\mathrm{OD}_{660}=0.5-0.6\right)$ of B. longum 105-A wild-type and B. longum 105-A $\Delta c p s D$ mutant. The RNA was stabilized before extraction with RNA Protect Bacteria Reagent (Qiagen). The cells were enzymatically lysed with $2 \mathrm{mg} / \mathrm{ml}$ Labiase (Cosmobio, Japan) followed by mechanical disruption of the cells using a beads beader [100]. Total RNA was extracted using the RNeasy Mini Kit (Qiagen). The genomic DNA contamination was removed by DNase treatment for two times using RNase-free DNaseI (Takara Bio Inc.). Reverse transcription was performed using Script Reverse Transcriptase (Bio-Rad Lab. Inc., Hercules, CA, USA). Expression of the cpsD gene (BL105A_0405), $B L 105 A$ _0406 gene (encoding the putative envelope protein), $B L 105 A \_0408$ gene (encoding the putative glycosyltransferase), BL105A_0414 gene (encoding the putative polymerase), $B L 105 A \_0424$ gene (encoding the putative dTDP-D-glucose 4,6-dehydratase) in both wild-type and mutant was quantified by qPCR on a real-time PCR system (StepOnePlus ${ }^{\mathrm{TM}}$, Thermo Fisher Scientific). The primers were designed using a primer analysis software (Oligo ver. 7, Molecular Biology Insights, Colorado Springs, CO, USA) to give amplicons of $80-150$ bp (Additional file 4: Table S1). Calibration curves were prepared in triplicate for each pair of primers. Dissociation curves were used to check the specificity of the amplicons. The qPCR reaction was performed using the THUNDERBIRD ${ }^{\circledR}$ SYBR qPCR Mix (Toyobo Co., Ltd.). The qPCR conditions were $95{ }^{\circ} \mathrm{C}$ for $20 \mathrm{~s}$ and 40 cycles of $95{ }^{\circ} \mathrm{C}$ for $10 \mathrm{~s}$ and $60{ }^{\circ} \mathrm{C}$ for $30 \mathrm{~s}$. All samples were assessed in triplicate. The gene expression was compared to the housekeeping gene, BL105A_1946 gene encoding RNase P, using the $2^{-\Delta \Delta C T}$ method [47]. 


\section{Resistance to low $\mathrm{pH}$}

To assess the resistance to Low $\mathrm{pH}$, logarithmic growth phase culture $\left(\mathrm{OD}_{660}=0.6\right)$ was harvested by centrifugation and re-suspended in fresh MRS medium, which had been adjusted to $\mathrm{pH} 3.5-5.0$ with $6 \mathrm{~N} \mathrm{HCl}$. Cell suspensions were incubated at $37^{\circ} \mathrm{C}$ for $2 \mathrm{~h}$ under anaerobic conditions. Then, they were serially diluted $\left(\times 10^{8}-10^{10}\right)$ and plated on MRS agar plates. The CFU were enumerated after overnight incubation at $37{ }^{\circ} \mathrm{C}$ [101]. For preincubation treatments, cultures were incubated in a fresh MRS medium, which had adjusted to $\mathrm{pH} 4.5$, at $37^{\circ} \mathrm{C}$ for $2 \mathrm{~h}$. The culture suspensions were then re-suspended in fresh MRS medium, adjusted to $\mathrm{pH} 3.5$, and incubated at $37^{\circ} \mathrm{C}$ for $2 \mathrm{~h}$. The CFUs of the sample were enumerated as above.

\section{Resistance to bile salt}

To assess the resistance to bile acid, the logarithmic growth phase culture $\left(\mathrm{OD}_{660}=0.6\right)$ was harvested by centrifugation and re-suspended in a fresh MRS medium adjusted from 1.0 to $3.0 \mathrm{~g} / \mathrm{L}$ with bile salt (Ox, Wako Pure Chemical Industries, Ltd., Osaka, Japan). Suspensions were incubated at $37{ }^{\circ} \mathrm{C}$ for $2 \mathrm{~h}$ and then serially diluted and plated on MRS agar plates. Plates were incubated overnight at $37^{\circ} \mathrm{C}$, and the $\mathrm{CFU}$ were enumerated. The experiments were performed in duplicate.

\section{Caco-2 cell line adhesion assay}

To determine the role of $B$. longum 105-A EPS in binding to the Caco-2 cell line, we performed the experiments according to the method published by Guglielmetti et al. [102]. Briefly, Caco-2 cells were cultured for 2 weeks at $37{ }^{\circ} \mathrm{C}$ in $5 \% \mathrm{CO}_{2}$ and moisture. This allowed for cellular differentiation and the development of microvilli. Caco-2 cells were then seeded onto $20 \mathrm{~mm} \phi$ coverslip, which had been coated with mouse collagen IV (Trevigen, Gaithersburg, MA, USA), in 12-well plate at $10^{5}$ cells per well, $24 \mathrm{~h}$ before being challenged with the bacteria. The cells were washed twice with PBS and kept in DMEM without antibiotics for $1 \mathrm{~h}$ before bacteria were added. Bacteria were inoculated overnight on MRS broth. MRS broth cultures were centrifuged; the bacterial pellets were washed twice with PBS and then re-suspended into prewarmed DMEM without antibiotics at an $\mathrm{OD}_{660}=0.7$. One milliliter of bacterial suspension was added to each well of Caco-2 cultures at a dose of $100 \mathrm{MOI}$, and then incubated anaerobically at $37{ }^{\circ} \mathrm{C}$ in $5 \% \mathrm{CO}_{2}$ and moisture for $1 \mathrm{~h}$. The cells were then washed 5 times with sterile PBS, fixed using 99.8\% methanol, and washed twice with PBS. Then the coverslips were incubated for $20 \mathrm{~min}$ with Giemsa stain (Muto Pure Chemicals, Tokyo, Japan) at a 1:10 dilution. After several washes with PBS, the coverslips were mounted with mount-quick (Daido Sangyo
Co., Ltd., Tokyo, Japan) and examined using phase contrast on a microscope (BX-43, Olympus Co., Tokyo, Japan).

\section{Macrophage phagocytosis assays}

To determine the role of B. longum 105-A's CPS in the interaction of the bacteria with non-specific immune cells, we performed the antibiotic protection assay as described previously by Chapot-Chartier et al. [74], with some modification. Briefly, we cultured RAW 264.7 murine macrophage cells in Dulbecco's Modified Eagle Medium with high glucose (DMEM, Sigma-Aldrich, St. Louis, MO, USA) at $37{ }^{\circ} \mathrm{C}$ in a $5 \% \mathrm{CO}_{2}$ and moisture. RAW 264.7 cells were seeded into collagen-coated coverslips in 24-well plates at $2.6 \times 10^{5} \mathrm{cell} / \mathrm{cm}^{2}$. The cells were challenged with an MOI of 100 for $30 \mathrm{~min}$. The noninternalized bacteria were removed by washing the cells five times with warmed PBS, and then $1 \mathrm{ml}$ of DMEM medium containing $250 \mu \mathrm{g} / \mathrm{ml}$ gentamicin was added. The cells were incubated at $37^{\circ} \mathrm{C}$ for $2 \mathrm{~h}$ to kill the extracellular bacteria. The cells were then washed and stained as specified above in Caco- 2 cell line adhesion assays.

The Caco-2 and macrophage media were supplemented with $10 \%(\mathrm{v} / \mathrm{v})$ heat-inactivated fetal bovine serum, $1.5 \mathrm{mM} \mathrm{L}$-glutamine, $1 / 100$ volume of non-essential amino acid (Sigma-Aldrich), 1/100 volume of PenicillinStreptomycin (10,000 U/ml, Thermo Fisher Scientific).

\section{Statistical analysis}

The difference in the expression levels of the downstream genes of cpsD BL105A_0406, BL105A_0408 BL105A_0414, and BL105A_0424 was analyzed by the Student $\mathrm{t}$ test.

\section{Additional files}

Additional file 1: Figure S2. SOSUI prediction of the membrane protein in B. longum 105-A. The protein of the gene BL105A_0405 (cpsD) to BL105A_0407 and BL105A_0414 to BL105A_0415 are the membrane protein.

Additional file 2: Figure S4. Characteristic features of $B$. longum wildtype strain and its $\triangle c p s D$ mutant in growth medium. (a) The growth curves of the wild-type $B$. longum strain and the $B$. longum 105-A $\triangle c p s D$ mutant strain were similar. (b) The cells of $\triangle \operatorname{cps} D$ mutant quickly sediment after stationery phase in liquid medium while the wild-type strain remained in suspension. (c) Measurements OD 660nm of wild-type B. longum strain and the B. longum 105-A $\triangle \operatorname{cps} D$ mutant over a panel time point grown ii liquid culture without agitation; the detected decrease in OD values for $B$. longum 105-A $\triangle \operatorname{cps} D$ mutant is due to cell sedimentation.

Additional file 3: Figure S3. HPLC analysis of EPS derived from $B$. longum 105-A wild-type its $\triangle c p s D$ mutant. A: Chromatogram of the monosaccharides in hydrolysates of the EPS from wild-type $B$. longum 105-A (blue line) and B. longum 105-A $\triangle \operatorname{cps} D$ mutant (red line). The chromatography was performed with Asahipak GS-220 HQ column $(300 \times 7.5$ $\mathrm{mm}$ ) and monitored by a fluorescent detector (Excitation: $331 \mathrm{~nm}$, Emission: 383 nm). Peak 1, galacturonic acid; Peak 2, glucose and galactose; Peak 3 and 4, are unknown. B: Chromatogram of the monosaccharides 
in hydrolysates of the EPS from wild-type B. longum 105-A (blue line) and $B$. longum 105-A $\triangle c p s D$ mutant (red line) for separating the glucose and galactose. The chromatography was performed with YMC-Pack NH2 column $(250 \times 4.6 \mathrm{~mm})$ and monitored by a fluorescent detector (Excitation: $331 \mathrm{~nm}$, Emission: $383 \mathrm{~nm}$ ). The ratio of Glc: Gal was 1:1.48 in the wild-type, while it was $1: 1.76$ in its $\triangle c p s D$ mutant. Peak 1, glucose; Peak 2, galactose. C: Chromatogram of the molecular weight distribution of the EPS from wild-type B. longum 105-A (black line) and B. longum 105-A $\triangle c p s D$ mutant (red line). The chromatography was performed with SUGAR KS-804 column $(300 \times 8.0 \mathrm{~mm})$ and monitored by a refractive index detector. Average molecular weight: Peak 1, 500 kDa; Peak 2, 200 kDa.

Additional file 4: Table S1. Primers used in this study.

Additional file 5: Figure S1. Schematic presentation of gene Knockout construction of cpsD. About 1 kb length upstream (BL105A_403, transposase) and downstream (BL105A_406, 406) regions were amplified and introduced into the franking regions of Spr marker on pKO403-Cm (1) (Sakaguchi), which carries temperature sensitive reprocation origin (Ori Ts) and $\mathrm{Cm}^{r}$ marker. The obtained plasmid (pKO403- $\Delta c \mathrm{cp} D$ ) was introduced into $B$. longum 105-A, then selected on MRS+Sp plate at $42^{\circ} \mathrm{C}$. Obtained recombinants should consist of $\mathrm{Sp}^{r}$ and $\mathrm{Cm}^{r}$ single cross over $(\mathrm{SCO})$ clones and $\mathrm{Sp}^{\mathrm{r}}$ and $\mathrm{Cm}^{\mathrm{s}}$ double cross over (DCO) clones. DCO clone was selected by by the replica selection with MRS+Sp and $\mathrm{Cm}$ plate. Obtained DCO clone was confirmed by PCR and DNA sequencing and designated $B$. longum 105-A $\triangle c p s D$.

\section{Abbreviations}

CPS: capsular polysaccharide; EPS: exopolysaccharide; bp: base pairs; CFU: colony-forming unit; OTU: operational taxonomic unit; PCR: polymerase chain reaction; PBS: phosphate buffered saline; DMEM: Dulbecco's Modified Eagle Medium with high glucose; qPCR: quantitative PCR; Sp: spectinomycin; $\mathrm{Cm}$ : chloramphenicol; TEM: transmission electron microscopy; PTA: phosphotungstic acid; OD660: optical density at $660 \mathrm{~nm}$; MOI: multiplicity of infection; MIC: mobile integrase cassette; HPLC: high-performance liquid chromatography; GTF: glycosyltransferase.

\section{Authors' contributions}

AT, HM, and TS contributed to the conception and design of the study. HM and IN performed deletion mutant construction. AT and HES performed function analyses. RPH and KK performed electron microscopy work. TY contributed polysaccharide analysis. AT, HM, HES, and TS analyzed the data and wrote the manuscript. TG and MI contributed to manuscript revision. TS obtained funding. All authors read and approved the final manuscript.

\section{Author details \\ 1 Faculty of Applied Biological Sciences, Gifu University, 1-1 Yanagido, Gifu 501-1193, Japan. ${ }^{2}$ Faculty of Veterinary Medicine, Kafr El-Sheikh University, Kafr El-Sheikh 33516, Egypt. ${ }^{3}$ Department of Chemistry and Bio- molecular Science, Faculty of Engineering, Gifu University, 1-1 Yanagido, Gifu 501-1193, Japan. ${ }^{4}$ CALM_live Imaging Facility, Centre for Inflammation Research, University of Edinburgh, Edinburgh 47 EH16 4TJ, UK. ${ }^{5}$ Depart- ment of Molecular Pathobiochemistry, Graduate School of Medicine, Gifu University, 1-1 Yanagido, Gifu 501-1193, Japan. ${ }^{6}$ United Graduate School of Drug Discovery and Medical Information Sciences, Gifu University, 1-1 Yanagido, Gifu 501-1193, Japan. ${ }^{7}$ Department of Gene and Development, Graduate School of Medicine, Gifu University, 1-1 Yanagido, Gifu 501-1193, Japan. ${ }^{8}$ Center for Highly Advanced Integration of Nano and Life Sciences, Gifu University (G-CHAIN), Gifu University, 1-1 Yanagido, Gifu 501-1193, Japan. ${ }^{9}$ United Graduate School of Agricultural Science, Gifu University, 1-1 Yanagido, Gifu 501-1193, Japan.}

\section{Acknowledgements}

We thank the following individuals at Gifu University: Moe Takeuchi and Saki Gotoh for sugar analysis. Drs. Yuji O. Kamatari and Koji Kitaguchi for critical discussion. Ayako Izumi, Yuka Takiguchi, and Dr. Kota Sakaguchi for developing genetic tools in Bifidobacterium.

\section{Competing interests}

The authors declare that they have no competing interests.

\section{Ethics approval and consent to participate}

The study was carried out in strict accordance with the recommendations specified in the Law Concerning the Conservation and Sustainable Use of Biological Diversity through Regulations on the Use of Living Modified Organisms, Japan. The project was reviewed and approved by the Gifu University Biosafety and Biosecurity Committee before the commencement of the research.

\section{Funding}

This work was supported by JSPS KAKENHI, with Grant Numbers JP25292048 and JP16H04896. This work was also partially supported by a research grant from The Skylark Food Science Institute.

\section{Publisher's Note}

Springer Nature remains neutral with regard to jurisdictional claims in published maps and institutional affiliations.

Received: 12 February 2017 Accepted: 21 April 2017

Published online: 01 May 2017

\section{References}

1. Walker AW, Lawley TD. Therapeutic modulation of intestinal dysbiosis. Pharmacol Res. 2013;69:75-86.

2. Scholtens PAMJ, Oozeer R, Martin R, Amor K Ben, Knol J. The early settlers: Intestinal microbiology in early life. Annu Rev Food Sci Technol. 2012;3:425-47. http://www.annualreviews.org/doi/abs/10.1146/ annurev-food-022811-101120.

3. Lane JA, Mehra RK, Carrington SD, Hickey RM. The food glycome: a source of protection against pathogen colonization in the gastrointestinal tract. Int J Food Microbiol. 2010;142:1-13.

4. Mitsuoka T. Establishment of intestinal bacteriology. Biosci Microbiota Food Health. 2014;33:99-116.

5. Jandhyala SM. Role of the normal gut microbiota. World J Gastroenterol. 2015;21:8787.

6. Rajilić-Stojanović M, de Vos WM. The first 1000 cultured species of the human gastrointestinal microbiota. FEMS Microbiol Rev. 2014;38:996-1047.

7. $\mathrm{FAO}, \mathrm{WHO}$. Health and nutritional properties of probiotics in food including powder milk with live lactic acid bacteria. Report of a Joint FAO/WHO expert consultation on evaluation of health and nutritional properties of probiotics in food including powder milk with live lactic acid bacteria. Córdoba, Argentina; 2001. p. 1-34. http://scholar.google. $\mathrm{com} / \mathrm{scholar}$ ?hl=en\&btnG=Search\&q=intitle:Health+and+Nutritional +Properties+of+Probiotics+in+Food+including+Powder+Milk+wit $h+$ Live+Lactic+Acid+Bacteria\#2\%5Cn.

8. Fuller R. Probiotics in man and animals. J Appl Bacteriol. 1989;66:365-78.

9. Kishi A, Uno K, Matsubara Y, Okuda C, Kishida T. Effect of the oral administration of Lactobacillus brevis subsp. coagulans on interferon-a producing capacity in humans. J Am Coll Nutr. 1996;15:408-12. https:// www.scopus.com/inward/record.uri?eid=2-s2.0-0029813798\&partnerl $\mathrm{D}=40 \& \mathrm{md5}=1703 \mathrm{~d} 7 \mathrm{e} 7 \mathrm{dd} 636656 \mathrm{cf36df5861a31a0e.}$

10. Xiao JZ, Kondo S, Yanagisawa N, Takahashi N, Odamaki T, Iwabuchi $\mathrm{N}$, et al. Effect of probiotic Bifidobacterium longum BB536 in relieving clinical symptoms and modulating plasma cytokine levels of Japanese cedar pollinosis during the pollen season. A randomized double-blind, placebo-controlled trial. J Investig Allergol Clin Immunol. 2006;16:86-93.

11. Grüber C, Wendt M, Sulser C, Lau S, Kulig M, Wahn U, et al. Randomized, placebo-controlled trial of Lactobacillus rhamnosus GG as treatment of atopic dermatitis in infancy. Allergy. 2007;62:1270-6. doi:10.1111/j.1398-9995.2007.01543.x.

12. Stenman LK, Waget A, Garret C, Klopp P, Burcelin R, Lahtinen S. Potential probiotic Bifidobacterium animalis ssp. lactis 420 prevents weight gain and glucose intolerance in diet-induced obese mice. Benef Microbes. 2014;5:437-45. doi:10.3920/BM2014.0014.

13. Miguel M, Recio I, Ramos M, Delgado MA, Aleixandre MA. Antihypertensive effect of peptides obtained from Enterococcus faecalis-fermented milk in rats. J Dairy Sci. 2006;89:3352-9. doi:10.3168/jds.S0022-0302(06)72372-4. 
14. Prasad J, Gill H, Smart J, Gopal PK. Selection and characterisation of Lactobacillus and Bifidobacterium strains for use as probiotics. Int Dairy J. 1999:8:993-1002.

15. Shah NP. Probiotic bacteria: selective enumeration and survival in dairy foods. J Dairy Sci. 2000:83:894-907.

16. Turnbaugh PJ, Gordon Jl. The core gut microbiome, energy balance and obesity. J Physiol. 2009:587:4153-8.

17. Hidalgo-Cantabrana C, Sánchez B, Milani C, Ventura M, Margolles A, Ruas-Madiedo P. Genomic overview and biological functions of exopolysaccharide biosynthesis in Bifidobacterium spp. Appl Environ Microbiol. 2014:80:9-18. doi:10.1128/AEM.02977-13.

18. Orla-Jensen ML. La classification des bactéries lactiques. Le Lait. 1924;4:468-74. doi:10.1051/lait:19243627.

19. Kopecný J, Mrázek J, Killer J. The presence of bifidobacteria in social insects, fish and reptiles. Folia Microbiol. 2010;55:336-9.

20. Bottacini F, Ventura M, van Sinderen D, O'Connell Motherway M. Diversity, ecology and intestinal function of bifidobacteria. Microb Cell Factories. 2014;13(Suppl 1):S4.

21. Rivière A, Selak M, Lantin D, Leroy F, De Vuyst L. Bifidobacteria and butyrate-producing colon bacteria: importance and strategies for their stimulation in the human gut. Front Microbiol. 2016;7:979.

22. Tabbers MM, de Milliano I, Roseboom MG, Benninga MA. Is Bifidobacterium breve effective in the treatment of childhood constipation? Results from a pilot study. Nutr J. 2011;10:19.

23. Gilman J, Cashman KD. The effect of probiotic bacteria on transepithelial calcium transport and calcium uptake in human intestinal-like Caco-2 cells. Curr Issues Intest Microbiol. 2006;7:1-5.

24. Ishikawa H, Akedo I, Umesaki Y, Tanaka R, Imaoka A, Otani T. Randomized controlled trial of the effect of bifidobacteria-fermented milk on ulcerative colitis. J Am Coll Nutr. 2003;22:56-63. doi:10.1080/073157 24.2003.10719276.

25. Coakley M, Banni S, Johnson MC, Mills S, Devery R, Fitzgerald G, et al. Inhibitory effect of conjugated a-linolenic acid from bifidobacteria of intestinal origin on SW480 cancer cells. Lipids. 2009;44:249-56. doi:10.1007/s11745-008-3269-z

26. Sivan A, Corrales L, Hubert N, Williams JB, Aquino-Michaels K, Earley ZM et al. Commensal Bifidobacterium promotes antitumor immunity and facilitates anti-PD-L1 efficacy. Science. 2015;350:1084-9. http://www. sciencemag.org/content/350/6264/1084.full.

27. Ivanov D, Emonet C, Foata F, Affolter M, Delley M, Fisseha M, et al. A serpin from the gut bacterium Bifidobacterium longum inhibits eukaryotic elastase-like serine proteases. J Biol Chem. 2006:281:17246-52.

28. Fukuda S, Toh H, Hase K, Oshima K, Nakanishi Y, Yoshimura K, et al. Bifidobacteria can protect from enteropathogenic infection through production of acetate. Nature. 2011;469:543-7. http://www.nature. com/nature/journal/v469/n7331/full/nature09646.html.

29. Klijn A, Mercenier A, Arigoni F. Lessons from the genomes of bifidobacteria. FEMS Microbiol Rev. 2005;29:491-509.

30. Salazar N, Ruas-Madiedo P, Kolida S, Collins M, Rastall R, Gibson G, et al. Exopolysaccharides produced by Bifidobacterium longum IPLA E44 and Bifidobacterium animalis subsp. lactis IPLA R1 modify the composition and metabolic activity of human faecal microbiota in $\mathrm{pH}$-controlled batch cultures. Int J Food Microbiol. 2009;135:260-7.

31. Fanning S, Hall $\sqcup$, Cronin M, Zomer A, MacSharry J, Goulding D, et al. Bifidobacterial surface-exopolysaccharide facilitates commensal-host interaction through immune modulation and pathogen protection. Proc Natl Acad Sci USA. 2012;109:2108-13.

32. Rehm BHA. Bacterial polymers: biosynthesis, modifications and applications. Nat Rev Microbiol. 2010;8:578-92. doi:10.1038/nrmicro2354.

33. Freitas F, Alves VD, Reis MAM. Advances in bacterial exopolysaccharides: from production to biotechnological applications. Trends Biotechnol. 2011:29:388-98

34. Jolly L, Vincent SJF, Duboc P, Neeser J-R. Exploiting exopolysaccharides from lactic acid bacteria. Antonie van Leeuwenhoek. 2002;82:367-74. doi:10.1023/A:1020668523541

35. Tone-Shimokawa Y, Toida T, Kawashima T. Isolation and structural analysis of polysaccharide containing galactofuranose from the cell walls of Bifidobacterium infantis. J Bacteriol. 1996;178:317-20.

36. Iwasaki H, Araki Y, Ito E, Nagaoka M, Yokokura T. Structure of macroamphiphiles from several Bifidobacterium strains. J Bacteriol. 1990;172:845-52.
37. Fischer W. "Lipoteichoic acid" of Bifidobacterium bifidum subspecies pennsylvanicum DSM 20239. A lipoglycan with monoglycerophosphate side chains. Eur J Biochem. 1987;165:639-46.

38. Fischer W, Bauer W, Feigel M. Analysis of the lipoteichoic-acid-like macroamphiphile from Bifidobacterium bifidum subspecies pennsylvanicum by one- and two-dimensional ${ }^{1} \mathrm{H}$ - and ${ }^{13} \mathrm{C}-\mathrm{NMR}$ spectroscopy. Eur J Biochem. 1987:165:647-52.

39. Habu Y, Nagaoka M, Yokokura T, Azuma I. Structural studies of cell wall polysaccharides from Bifidobacterium breve YIT 4010 and related Bifidobacterium species. J Biochem. 1987;102:1423-32.

40. Den Camp HJMO, Veerkamp JH, Oosterhof A, van Halbeek H. Structure of the lipoteichoic acids from Bifidobacterium bifidum spp pennsylvanicum. Biochimica et Biophysica Acta. 1984;795:301-13.

41. Patel S, Majumder A, Goyal A. Potentials of exopolysaccharides from lactic acid bacteria. Indian J Microbiol. 2012;52:3-12. doi:10.1007/ s12088-011-0148-8.

42. Ross Watson R, Preedy VR. Probiotics, prebiotics, and synbiotics: bioactive foods in health promotion. The mediterranean diet: an evidencebased approach. Amsterdam: Academic Press; 2016. p. 909.

43. Conover MS, Sloan GP, Love CF, Sukumar N, Deora R. The Bps polysaccharide of Bordetella pertussis promotes colonization and biofilm formation in the nose by functioning as an adhesin. Mol Microbiol. 2010;77:1439-55. doi:10.1111/j.1365-2958.2010.07297.x.

44. Mazmanian SK, Liu CH, Tzianabos AO, Kasper DL. An immunomodulatory molecule of symbiotic bacteria directs maturation of the host immune system. Cell. 2005;122:107-18.

45. Lei L, Yang Y, Mao M, Li H, Li M, Yang Y, et al. Modulation of biofilm exopolysaccharides by the Streptococcus mutans vic $X$ gene. Front Microbiol. 2015. doi:10.3389/fmicb.2015.01432/abstract.

46. Surayot U, Wang J, Seesuriyachan P, Kuntiya A, Tabarsa M, Lee Y, et al. Exopolysaccharides from lactic acid bacteria: Structural analysis, molecular weight effect on immunomodulation. Int J Biol Macromol. 2014:68:233-40

47. Dertli E, Mayer MJ, Narbad A. Impact of the exopolysaccharide layer on biofilms, adhesion and resistance to stress in Lactobacillus johnsonii Fl9785. BMC Microbiol. 2015;15:8.

48. Lucey M, Daly C, Fitzgerald GF. Cell surface characteristics of Lactococcus lactis harbouring pCl528, a 46 kb plasmid encoding inhibition of bacteriophage adsorption. J General Microbiol. 1992;138:2137-43. doi:10.1099/00221287-138-10-2137.

49. Ferrario C, Milani C, Mancabelli L, Lugli GA, Duranti S, Mangifesta $M$, et al. Modulation of the eps-ome transcription of bifidobacteria through simulation of human intestinal environment. FEMS Microbiol Ecol. 2016:92:fiw056.

50. Schell M, Karmirantzou M, Snel B, Vilanova D, Berger B, Pessi G, et al. The genome sequence of Bifidobacterium longum reflects its adaptation to the human gastrointestinal tract. Proc Natl Acad Sci USA. 2002:99:14422-7. doi:10.1073/pnas.212527599.

51. Guglielmetti S, Mayo B, Álvarez-Martín P. Mobilome and genetic modification of bifidobacteria. Benef Microbes. 2013;4:143-66. doi:10.3920/ BM2012.0031.

52. Brancaccio VF, Zhurina DS, Riedel CU. Tough nuts to crack: site-directed mutagenesis of bifidobacteria remains a challenge. Bioengineered. 2013;4:197-202. doi:10.4161/bioe.23381.

53. Yasui K, Kano Y, Tanaka K, Watanabe K, Shimizu-Kadota M, Yoshikawa H, et al. Improvement of bacterial transformation efficiency using plasmid artificial modification. Nucleic Acids Res. 2009;37:e3.

54. Suzuki T, Yasui K. Plasmid artificial modification: a novel method for efficient DNA transfer into bacteria. Methods Mol Biol. 2011. doi:10.1007/978-1-61779-197-0_18.

55. Sakaguchi K, He J, Tani S, Kano Y, Suzuki T. A targeted gene knockout method using a newly constructed temperature-sensitive plasmid mediated homologous recombination in Bifidobacterium longum. Appl Microbiol Biotechnol. 2012;95:499-509.

56. Sakaguchi K, Funaoka N, Tani S, Hobo A, Mitsunaga T, Kano Y, et al. The pyrE gene as a bidirectional selection marker in Bifidobacterium longum 105-A. Biosci Microbiota Food Health. 2013;32:59-68.

57. He J, Sakaguchi K, Suzuki T. Determination of the ribosome-binding sequence and spacer length between binding site and initiation codon for efficient protein expression in Bifidobacterium longum 105-A. J Biosci Bioeng. 2012;113:442-4 
58. He J, Sakaguchi K, Suzuki T. Acquired tolerance to oxidative stress in Bifidobacterium longum 105-A via expression of a catalase gene. Appl Environ Microbiol. 2012;78:2988-90. doi:10.1128/ AEM.07093-11.

59. Hirayama Y, Sakanaka M, Fukuma H, Murayama H, Kano Y, Fukiya S, et al. Development of a double-crossover markerless gene deletion system in Bifidobacterium longum: functional analysis of the a-galactosidase gene for raffinose assimilation. Appl Environ Microbiol. 2012;78:498494. doi:10.1128/AEM.00588-12.

60. Matsumura H, Takeuchi A, Kano Y. Construction of Escherichia coli-Bifidobacterium longum shuttle vector transforming B. longum 105-A and 108-A. Biosci Biotechnol Biochem. 1997;61:1211-2. doi:10.1271/bbb.61.1211.

61. Kanesaki Y, Masutani H, Sakanaka M, Shiwa Y, Fujisawa T, Nakamura Y, et al. Complete genome sequence of Bifidobacterium longum 105-A, a strain with high transformation efficiency. Genome Announc. 2014;2:e01311.

62. Ruas-Madiedo P, Salazar N, de los Reyes-Gavilán CG. Biosynthesis and chemical composition of expolysaccharides produced by lactic acid bacteria. In: Ullrich M, editor. Bacterial polysaccharides: current innovations and future trends. Poole: Caister Academic Press; 2009. p. 279-310. http://www.caister.com/hsp/abstracts/polysaccharides/16.html.

63. Klaenhammer TR, Barrangou R, Buck BL, Azcarate-Peril MA, Altermann E. Genomic features of lactic acid bacteria effecting bioprocessing and health. FEMS Microbiol Rev. 2005;29:393-409.

64. Lebeer S, Verhoeven TLA, Francius G, Schoofs G, Lambrichts I, Dufrêne $Y$, et al. Identification of a gene cluster for the biosynthesis of a long, galactose-rich exopolysaccharide in Lactobacillus rhamnosus. Appl Environ Microbiol. 2009;75:3554-63.

65. LaPointe G, Atlan D, Gilbert C. Characterization and site-directed mutagenesis of Wzb, an O-phosphatase from Lactobacillus rhamnosus. BMC Biochem. 2008;9:10.

66. Morona JK, Morona R, Paton JC. Attachment of capsular polysaccharide to the cell wall of Streptococcus pneumoniae type 2 is required for invasive disease. Proc Natl Acad Sci USA. 2006;103:8505-10. http://www. pnas.org/content/103/22/8505.full.

67. Whitfield C, Paiment A. Biosynthesis and assembly of Group 1 capsular polysaccharides in Escherichia coli and related extracellular polysaccharides in other bacteria. Carbohydr Res. 2003;338:2491-502.

68. Nagaoka M, Shibata H, Kimura I, Hashimoto S, Kimura K, Sawada H, et al. Structural studies on a cell wall polysaccharide from Bifidobacterium longum YIT4028. Carbohydr Res. 1995;274:245-9.

69. Bentley SD, Aanensen DM, Mavroidi A, Saunders D, Rabbinowitsch E, Collins M, et al. Genetic analysis of the capsular biosynthetic locus from all 90 pneumococcal serotypes. PLoS Genet. 2006;2:e31.

70. Altmann F, Kosma P, O'Callaghan A, Leahy S, Bottacini F, Molloy E, et al. Genome analysis and characterisation of the exopolysaccharide produced by Bifidobacterium longum subsp longum $35624^{\mathrm{TM}}$. PLOS ONE. 2016;11:0162983.

71. Woeste S, Demchick P. New version of the negative stain. Appl Environ Microbiol. 1991;57:1858-9.

72. Sengupta R, Altermann E, Anderson RC, McNabb WC, Moughan PJ, Roy NC. The role of cell surface architecture of lactobacilli in hostmicrobe interactions in the gastrointestinal tract. Mediators Inflamm. 2013;2013:237921.

73. Wang H, Wilksch JJ, Strugnell RA, Gee ML. Role of capsular polysaccharides in biofilm formation: an AFM nanomechanics study. ACS Appl Mater Interfaces. 2015;7:13007-13.

74. Chapot-Chartier M-P, Vinogradov E, Sadovskaya I, Andre G, Mistou M-Y, Trieu-Cuot P, et al. Cell surface of Lactococcus lactis is covered by a protective polysaccharide pellicle. J Biol Chem. 2010;285:10464-71.

75. Aminov Rl. Horizontal gene exchange in environmental microbiota. Front Microbiol. 2011;2:158.

76. Lee J-H. OSullivan DJ. Genomic insights into bifidobacteria. Microbiol Mol Biol Rev. 2010;74:378-416.

77. Lee J-H, Karamychev VN, Kozyavkin SA, Mills D, Pavlov AR, Pavlova NV, et al. Comparative genomic analysis of the gut bacterium Bifidobacterium longum reveals loci susceptible to deletion during pure culture growth. BMC Genom. 2008;9:247.

78. De Castro C, Gargiulo V, Lanzetta R, Parrilli M. Agrobacterium rubi T DSM 6772 produces a lipophilic polysaccharide capsule whose degree of acetylation is growth modulated. Biomacromolecules. 2007;8:1047-51. doi:10.1021/bm061081f.

79. Woo H-H. Meristem-localized inducible expression of a UDP-glycosyltransferase gene is essential for growth and development in Pea and Alfalfa. Plant Cell. 1999;11:2303-16. doi:10.1105/tpc.11.12.2303.

80. Sanchez B, Ruiz L, de los Reyes-Gavilan CG, Margolles A. Proteomics of stress response in Bifidobacterium. Front Biosci J Virtual Libr. 2007;13:6905-19.

81. González-Rodríguez I, Ruiz L, Gueimonde M, Margolles A, Sánchez B. Factors involved in the colonization and survival of bifidobacteria in the gastrointestinal tract. FEMS Microbiol Lett. 2013;340:1-10.

82. Fallingborg J, Christensen LA, Ingeman-Nielsen M, Jacobsen BA, Abildgaard $\mathrm{K}$, Rasmussen $\mathrm{HH}$, et al. Measurement of gastrointestinal $\mathrm{pH}$ and regional transit times in normal children. J Pediatr Gastroenterol Nutr. 1990;11:211-4.

83. Collado MC, Sanz Y. Induction of acid resistance in Bifidobacterium : a mechanism for improving desirable traits of potentially probiotic strains. J Appl Microbiol. 2007;103:1147-57. doi:10.1111/j.1365-2672.2007.03342.x.

84. Bini L, Gobbetti M, De Angelis M, Cocconcelli PS, Pallini V. The acidstress response in Lactobacillus sanfranciscensis CB1. Microbiology. 2001;147:1863-73.

85. Ruiz L, Margolles A, Sánchez B. Bile resistance mechanisms in Lactobacillus and Bifidobacterium. Front Microbiol. 2013. doi:10.3389/ fmicb.2013.00396/abstract.

86. Islam KBMS, Fukiya S, Hagio M, Fujii N, Ishizuka S, Ooka T, et al. Bile acid is a host factor that regulates the composition of the cecal microbiota in Rats. Gastroenterology. 2011;141:1773-81.

87. Begley M, Kerr C, Hill C. Exposure to bile influences biofilm formation by Listeria monocytogenes. Gut Pathogens. 2009;1:11. doi:10.1186/1757-4749-1-11.

88. Kumar S, Kumar S, Kumar S. Infection as a risk factor for gallbladder cancer. J Surg Oncol. 2006;93:633-9. doi:10.1002/jso.20530.

89. Gómez Zavaglia A, Kociubinski G, Pérez P, Disalvo E, De Antoni G. Effect of bile on the lipid composition and surface properties of bifidobacteria. J Appl Microbiol. 2002;93:794-9.

90. Ohman DE, Goldberg JB, Flynn JA, Powell SK. Genetics of exopolysaccharide production by mucoid Pseudomonas aeruginosa. Antibiot Chemother. 1985;36:13-22. doi:10.1007/BF02013452.

91. Flemming $\mathrm{H}$, Wingender J. The biofilm matrix. Nat Rev Microbiol. 2010;8:623-33. doi:10.1038/nrmicro2415.

92. Bernet MF, Brassart D, Neeser JR, Servin AL. Lactobacillus acidophilus LA 1 binds to cultured human intestinal cell lines and inhibits cell attachment and cell invasion by enterovirulent bacteria. Gut. 1994;35:483-9.

93. Lehto E. Inhibition of Salmonella typhimurium adhesion to Caco-2 cell cultures by Lactobacillus strain GG spent culture supernate: only a pH effect? FEMS Immunol Med Microbiol. 1997;18:125-32.

94. Lebeer S, Claes I, Tytgat HLP, Verhoeven TLA, Marien E, von Ossowski I, et al. Functional analysis of Lactobacillus rhamnosus GG pili in relation to adhesion and immunomodulatory interactions with intestinal epithelial cells. Appl Environ Microbiol. 2012;78:185-93.

95. Segers ME, Lebeer S. Towards a better understanding of Lactobacillus rhamnosus GG_host interactions. Microb Cell Factories. 2014;13:S7. doi:10.1186/1475-2859-13-S1-S7.

96. Wold AE. Immune effects of probiotics. Food Nutr Res. 2001;45:76-85. doi:10.3402/fnr.v45i0.1787.

97. Altschul SF, Gish W, Miller W, Myers EW, Lipman DJ. Basic local alignment search tool. J Mol Biol. 1990;215:403-10.

98. Hirokawa T, Boon-Chieng S, Mitaku S. SOSUI: classification and secondary structure prediction system for membrane proteins. Bioinformatics. 1998;14:378-9. http://bioinformatics.oxfordjournals. org/content/14/4/378. http://bioinformatics.oxfordjournals.org/content/14/4/378.full.pdf.

99. Engler C, Kandzia R, Marillonnet S. A one pot, one step, precision cloning method with high throughput capability. PloS ONE. 2008;3:e3647. doi:10.1371/journal.pone.0003647.

100. Yasui K, Tabata M, Yamada S, Abe T, Ikemura T, Osawa R, et al. Intraspecies diversity between seven Bifidobacterium adolescentis strains identified by genome-wide tiling array analysis. Biosci Biotechnol Biochem 2009;73:1422-4. http://joi.jlc.jst.go.jp/JST.JSTAGE/ $\mathrm{bbb} / 80843$ ?from $=$ CrossRef. 
101. Yang $X$, Hang $X$, Tan J, Yang H. Differences in acid tolerance between Bifidobacterium breve BB8 and its acid-resistant derivative $B$. breve BB8dpH, revealed by RNA-sequencing and physiological analysis. Anaerobe. 2015;33:76-84.
102. Guglielmetti S, Tamagnini I, Mora D, Minuzzo M, Scarafoni A, Arioli $\mathrm{S}$, et al. Implication of an outer surface lipoprotein in adhesion of Bifidobacterium bifidum to Caco-2 cells. Appl Environ Microbiol. 2008;74:4695-702. 